Article

\title{
Multi-Objective Approach for Optimization of City Logistics Considering Energy Efficiency
}

\author{
Mohammad Zaher Akkad $[$ and Tamás Bányai * $*$ \\ Institute of Logistics, University of Miskolc, 3515 Miskolc, Hungary; zaherakkad91@gmail.com \\ * Correspondence: alttamas@uni-miskolc.hu
}

Received: 13 August 2020; Accepted: 3 September 2020; Published: 8 September 2020

\begin{abstract}
Urban population increase results in more supply chain operations in these areas, which leads to increased energy consumption and environmental pollution. City logistics represents a strategy of efficient freight transportation and material handling to fulfill customer and business demands. Within the frame of this paper, the authors describe an optimization model of a multi-echelon collection and distribution system, focusing on downtown areas and energy efficiency, sustainability, and emission reduction. After a systematic literature review, this paper introduces a mathematical model of collection and distribution problems, including package delivery, municipal waste collection, home delivery services, and supply of supermarkets and offices. The object of the optimization model is twofold: firstly, to design the optimal structure of the multi-echelon collection and distribution system, including layout planning and the determination of required transportation resources, like e-cars, e-bikes, and the use of public transportation; and secondly, to optimize the operation strategy of the multi-echelon supply chain, including resource allocation and scheduling problems. Next, a heuristic approach is described, whose performance is validated with common benchmark functions, such as metaheuristic evaluation. The scenario analysis demonstrates the application of the described model and shows the optimal layout, resource allocation, and operation strategy focusing on energy efficiency.
\end{abstract}

Keywords: city logistics; emission reduction; energy-efficient transportation; multi-echelon supply

\section{Introduction}

City logistics field has become more forked with numerous available solutions within the last few years due to recent successive innovations in transportation and Industry 4.0. The pace of renewable energy developments in transportation such as e-cars and e-bikes are increasing and it has opened wide scope to the possibility of using them, next to the Industry 4.0 technologies that rely on the Internet of Things and artificial intelligence, which help to innovate smart solutions support the aim of shortening the needed time and route distance with collecting and saving information, giving the ability to analyze them. Furthermore, sustainability is an important topic that is taking priority within current world development goals. Working on reducing spent energy, emissions, and pollution is always highly recommended for its positive impact on the environment and climate, converting the existing world into a more sustainable one. Researching those modern solutions has dramatically increased in different aspects, releasing the importance of applying them to reality in a positive way. However, city logistics include different sections in urban areas, such as goods storage, waste collection, and home delivery service. It has been worked on optimizing the inventory and distribution logistics to give the maximum advantage. For instance, a multi-echelon inventory that raised the efficiency of collecting and distribution logistics by considering the entire supply network and managing the inventory in that network. 
It is possible to argue that Industry 4.0 technologies can pave the way for city logistics principles, for example by tracking products and gentelligent components. Gentelligent products are mechanical components that are featured to collect, save, and transmit information regarding design, manufacturing, distribution, use, and recycling. Gentelligent means that it is possible to define new strategies for the next product generation (genetic + intelligent) [1]. Nevertheless, due to the very recent development of these ideas, the relationship between the city logistics and Industry 4.0 technologies has not been widely evaluated, especially in finding out the optimized application of all these solutions with sustainable saving energy. Therefore, analyzing the used conventional city logistics ways and delivering mathematical optimization that combines saving time, saving energy, reducing emissions, reducing consumption, and raising positive environmental impact is the next step that should be tackled in order to have the scientific background that supports the implementation of this optimization in reality.

The literature introduces a wide range of areas and methods used to analyze, solve, and optimize city logistics in the transportation domain, like measurement, mathematical, heuristic optimization, statistical approaches, aggregate methods, or empirical studies. A proposed logistical structure in Rome was designed by Crainic et al. [2]. Algorithmic and implementation issues were discussed in that case. Taniguchi et al. presented a dynamic vehicle routing and scheduling model that incorporates real-time information using variable travel times [3]. The results indicated that, by comparing with the forecast model, the total cost decreased because of the scheduling model with real-time information and implementing the dynamic vehicle routing. Munuzuri et al. established a compilation of the solutions and initiatives from the urban communities' perspective [4], that can be implemented by local administrations in order to improve freight deliveries in urban environments. In studying regulations effect, Quak et al. [5] discussed the impact of governmental time-window pressure on retailers' logistical concepts and the consequential financial and environmental distribution performance, using collected data in the Netherlands. In a case study in Finland [6], Braysy et al. showed that there is a significant potential for cost savings in scheduling home care, transportation of the elderly, and home meal delivery using variant vehicle routing. Although the idea of load consolidation within the freight trucks was suggested to mitigate congestion and environmental impacts, Sathaye et al. studied different scenarios of applying this idea [7]. Different conclusions regarding estimated emissions resulting from load consolidation and changes in load factors were found, but it was also mainly found that applying this idea is not totally positive. Deflorio et al. proposed a simulation method [8] to obtain real-life scenarios for cost evaluation in this context and presents an application to a case study concerning a freight distribution service, which works on a broad road network that has a city center, a peripheral urban area, and a semi-urban country zone.

Lack of awareness has often restricted the sustainable urban freight management, not only on the local regulatory contexts, but regarding the acceptance and the effectiveness of the constraint of various distribution-chain stakeholders, especially the citizens who are usually overlooked [9], while policies have a great impact on performance as well. Study results point towards heterogeneity in policy acceptability and reveal different operator's stated reactions to innovative freight policies [10]. A solution was proposed by establishing a system of mini hubs, where delivery vehicles may park for the final deliveries to be completed on foot in urban areas [11], where many restrictions and regulations may be faced. Another study that dealt with the intelligent transportation systems (ITS) [12] used to improve the performance and safety of transport next to proposed models to forecast the freight transport demand resulted from changes in infrastructures, services, and regulation [13], while proposing a general scheduled service network design modeling framework that captures the fundamental concepts related to the definition of urban-vehicle tactical plans within a two-tier distribution network [14]. Different areas that are connected to city logistics were conducted within research such as multi-echelon [15-17], energy-efficient [18,19], and emission reduction [20,21].

Within the research topic of city logistics, different case studies were analyzed and published around the world. However, these case studies were dealing with a variety of points of view. 
There are cases in Beijing [22], Christchurch [23], Ghent [24], and Melbourne [25] for analyzing the effectiveness and system development. There are cases in Bogota [26,27] and Lyon [28] for measuring the environmental impact. There are cases in Santiago [29], Melbourne [30], and Cagliari [31] for investigating the last mile. There are cases in Venice Lagoon [32] and Ghent [33] for smart urban planning. There were other cases in Thessaloniki [34] for sustainability and in Lisbon [35] for analyzing the characteristics. Furthermore, due to widespread electric transportation use like an electric truck, e-car [36,37], and e-bike [38], there is a focus on this scope in scientific research recently [39] because of their reduced size, noise, and pollution. The behavior of transport companies regarding electric vehicles in the urban environment [40-42] was analyzed, while medium-duty vehicles are only financially competitive at higher mileages $[43,44]$ if the savings achieved by lower operational costs are greater than the costs for battery replacements, and it was worked on improving their performance and reducing the bad impact on the environment that results from the used batteries charging them [45-48]. This was a study of two-echelon distribution systems, whereas smaller vehicles allow reaching the final customers [49], bringing new managerial insights related to the incorporation of electric vehicles into two-echelon delivery networks [50]. Study results [51] show that it is expected to receive more benefits from environment-friendly vehicles by city users, while according to another study [52], the implementation of sustainable solutions is required, and there is a need to use an integrated modeling approach [53]. There are also cases where people and freight mobility in urban areas are successfully combined, like middle crowd shipping, carsharing, ridesharing, and carpooling experiences [54-57]. In city logistics, other combined problems like inventory routing and pick-up and delivery can also be taken into consideration [58-60]. The main findings of the above-mentioned review can be summarized as follows:

- The articles that addressed the city logistics from a sustainable point of view are focusing on conventional supply chain solutions.

- Few of the articles have aimed to provide an approach or to optimize the design of logistics networks within the urban areas while considering energy efficiency.

- The number of articles regarding city logistics has dramatically increased in the last few years.

- Energy efficiency becomes more and more important in the field of city logistics, while sustainability aspects are also taken into consideration.

- Multi-echelon solutions can improve energy efficiency and the sustainability of supply chains, and especially city logistics.

These findings are linked with previous review articles [61,62]; therefore, the optimization of city logistics considering energy efficiency still needs more attention and research.

After this introduction, the remaining parts of the paper are divided into five sections. Section 2 presents the model of a conventional city logistics solution and an evaluation methodology to create reference parameters for further comparison. Section 3 presents a methodology for the modeling and optimization of multi-echelon supply in downtown areas based on e-vehicles. Conclusions and future research directions are discussed in the last section.

The main contribution of this article includes: (1) a methodology to evaluate conventional city logistics solutions from time, distance, energy consumption and emission point of view; (2) a methodology to design and optimize multi-echelon city logistics solution, where capacity, timeliness, suitability, availability, and energy-related constraints are taken into consideration; (3) comparative analysis of conventional and multi-echelon e-vehicle-based city logistics solutions focusing on energy efficiency and emission reduction; and (4) computational results of different scenarios to validate the developed methodology.

\section{Problem Description}

In the case of conventional city logistics solutions, the supply of pick-up and delivery points (households, supermarkets, shops, etc.) is processed directly (Figure 1). However, more and more 
e-vehicles are adopted in supply chain solutions, but most of the cargo trucks are conventional diesel trucks. Their processes are optimized by the agents of each service provider, but the separated optimization without any cooperation leads to increased fuel consumption and emission. Within the frame of this section, an evaluation methodology is shown, which makes it possible to evaluate existing conventional city logistics solutions to define reference parameters for further comparison with the optimized system.

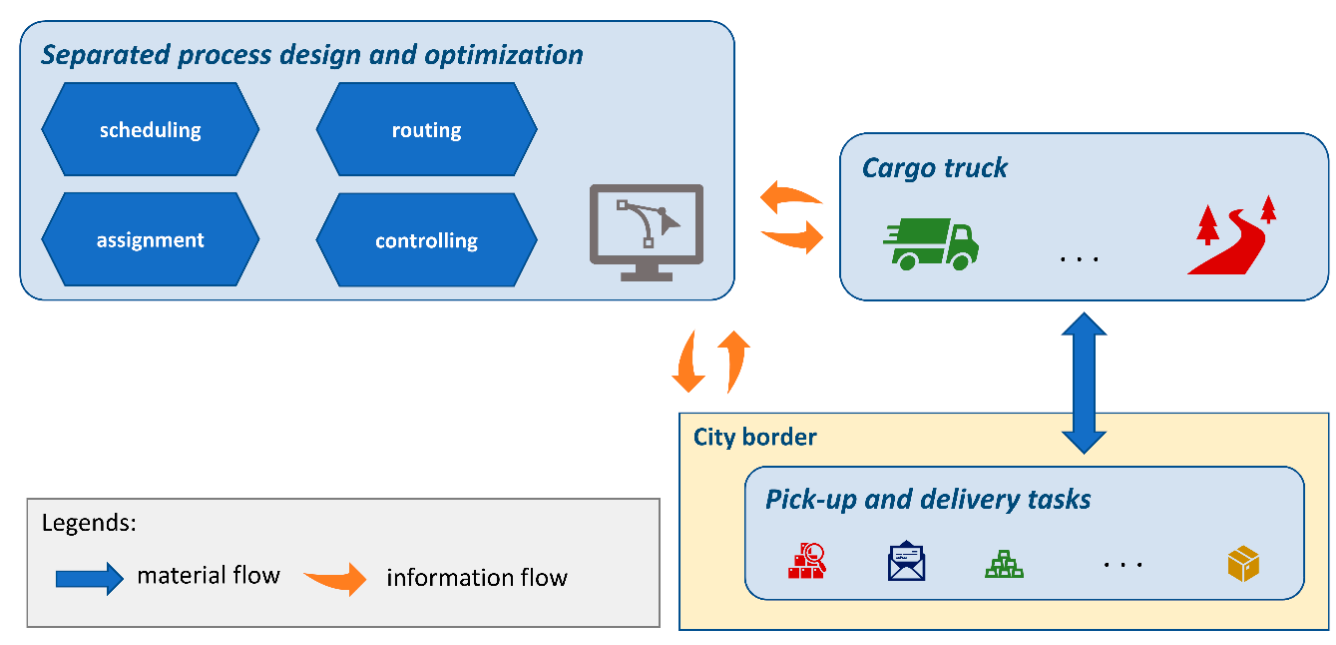

Figure 1. Conventional city logistics solution in Scenario 1.

Without any cooperation of large service providers and self-employed truck drivers, it is not possible to optimize this conventional solution. The optimization of each service provider is great from their point of view, but it has no significant impact on the emission reduction target. Meeting the targets of zero-emission in urban centers by 2030 [63], the below-described methodology makes it possible to find the bottlenecks of the system, which can have a great impact on the emission of the urban area.

In the second scenario, an optimization methodology for a multi-echelon city logistics solution is described. The external logistics service providers are transporting goods to/from logistics centers located outside of the urban area (city border). The collection and distribution of goods to/from pick-up and delivery points are processed from this intermediate storage directly by e-trucks and micro-mobility e-vehicles (Figure 2). The optimization of the whole process is centralized. It means that in this case, there is strong cooperation among transportation resources and not only the fuel consumption but also the emission of various greenhouse gases can be reduced.

The intelligent agent optimizes scheduling, assignment, routing layout design, and controlling tasks, that focus on time, distance, energy consumption, and emission-related objective functions, while capacity, availability, suitability, time-window, energy, and service level related constraints can limit the optimal solution.

This scenario focuses on an e-vehicle-based solution, where the efficiency of the whole system can be increased by using existing Industry 4.0 technologies, like smart devices, radiofrequency identification, digital twin solutions, and cloud and fog computing to solve big data problems of a large scale system, including a wide range of users, transportation resources and goods. 


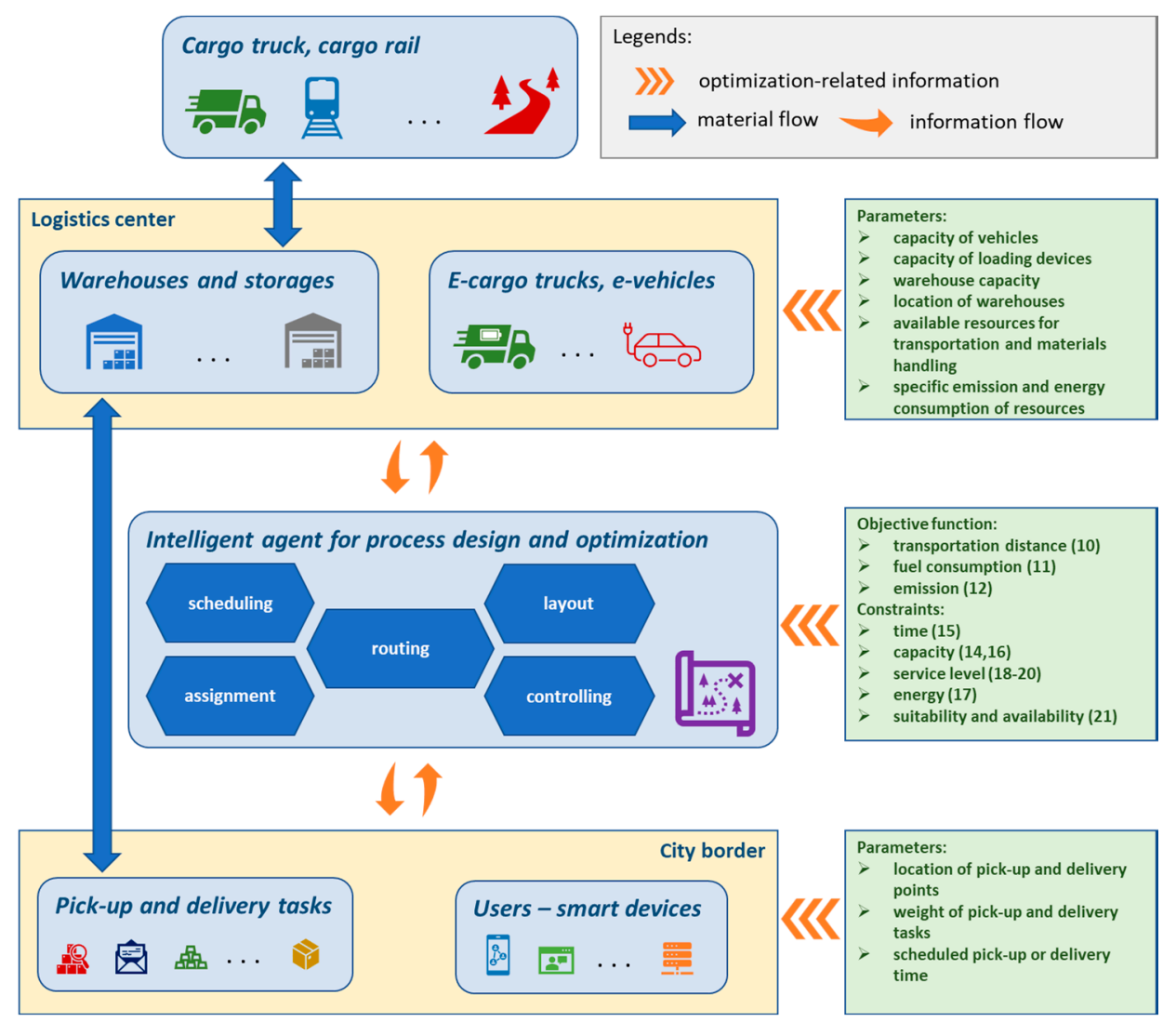

Figure 2. Model of multi-echelon collection and distribution system in downtown areas in Scenario 2.

\section{Evaluation of a Conventional City Logistics Solution}

The evaluation methodology focuses on time-, fuel- and emission-related objective functions, while no capacity, energy, availability, and time-related constraints are taken into consideration, because the system is in this case only evaluated and not optimized. Table A1 in Appendix A shows the nomenclature used in the mathematical model of the conventional city logistics solution.

The first parameter of the evaluation is the total length of transportation routes within the time span of analysis. The transportation is performed with conventional trucks, and no logistics center is taken into consideration for pick-up and delivery operations; all pick-up and delivery are performed by the trucks as direct supply. The parameter of the evaluation, in this case, can be written as follows:

$$
L=\sum_{\alpha=1}^{\alpha_{\max }} \sum_{\beta=1}^{\alpha} \beta_{\max }^{\alpha-1} l\left(p_{y_{x_{\alpha, \beta}^{*}},} p_{y_{x_{\alpha, \beta+1}^{*}}}\right)
$$

where $L$ is the total length of the transportation routes within the time span of optimization, $\alpha$ is the number of delivery trucks, $\beta_{\max }^{\alpha}$ is the number of pick-up and delivery points assigned to collection route $\alpha, x_{\alpha, \beta}^{*}$ is the ID number of pick-up and delivery task assigned to route $\alpha$ as pick-up or delivery task $\beta, y_{x_{\alpha, \beta}^{*}}$ defines the ID of pick-up or delivery point, $p_{y_{\alpha, \beta}^{*}}$ is the position of pick-up or delivery point assigned to route $\alpha$ as pick-up or delivery task $\beta$ and $l$ is the length of transportation route as a function of positions of pick-up and delivery points.

The second parameter of the evaluation is the fuel consumption, which can be calculated depending on the length of transportation routes, required material handling operations (loading and unloading), and the specific fuel consumption rate:

$$
C^{F U E L}=C_{T}^{F U E L}\left(l, v, c_{\alpha, \beta}^{F T}\right)+C_{M H}^{F U E L}\left(c_{\alpha, \beta}^{F M H}\right)
$$


where $C_{T}^{F U E L}$ is the fuel consumption of the whole transportation process without material handling (loading and unloading), $c_{\alpha, \beta}^{F T}$ is the specific fuel consumption of transportation, $C_{M H}^{F U E L}$ is the fuel consumption of material handling operations at the pick-up and delivery points, $c_{\alpha, \beta}^{F M H}$ is the specific fuel consumption regarding material handling operations and $v$ is the average speed of the truck.

The fuel consumption of the transportation process can be expressed as

$$
C_{T}^{F U E L}=\sum_{\alpha=1}^{\alpha_{\max }} \sum_{\beta=1}^{\alpha} \beta_{\max }^{\alpha}-1\left(p_{y_{\alpha, \beta}^{*}}, p_{y_{x_{\alpha, \beta+1}^{*}}}\right) \cdot q_{x_{\alpha, \beta}^{*}} \cdot c_{\alpha, \beta}^{F T}\left(q_{x_{\alpha, \beta}^{*}}\right)
$$

where $q_{\alpha, \beta}$ is the pick-up or delivery volume assigned to route $\alpha$ as pick-up or delivery task $\beta$.

The specific fuel consumption of the transportation process can be calculated as follows:

$$
c_{\alpha, \beta^{*}}^{F T}=c_{\alpha, \min }^{F T}+\frac{c_{\alpha, \max }^{F T}-c_{\alpha, \min }^{F T}}{c_{\alpha, \max }^{F T}} \cdot\left(q_{\alpha \max }^{T R A N S}-\sum_{\beta=1}^{\beta^{*}} q_{\alpha_{\alpha, \beta}^{*}}\right)
$$

where $c_{\alpha, \min }^{F T}$ and $c_{\alpha, \text { max }}^{F T}$ are the lower and upper limits of fuel consumption of transportation depending on the weight of loading, and $q_{\alpha \max }^{T R A N S}$ is the upper limit of the loading weight.

The fuel consumption of the loading and unloading operations performed by the truck mounted crane can be given by

$$
C_{M H}^{F U E L}=\sum_{\alpha=1}^{\alpha_{\max }} \sum_{\beta=1}^{\alpha} c_{\alpha, \beta}^{\alpha} c_{\alpha, \beta}^{F M H}\left(q_{x_{\alpha, \beta}^{*}}\right)
$$

The specific fuel consumption of material handling processes can be calculated as follows:

$$
c_{\alpha, \beta}^{F M H}=c_{\alpha, \min }^{F M H}+\frac{c_{\alpha, \max }^{F M H}-c_{\alpha, \min }^{F M H}}{c_{\alpha, \max }^{F M H}} \cdot\left(q_{\alpha \max }^{M H}-q_{\alpha_{\alpha, \beta}^{*}}\right)
$$

where $c_{\alpha, \min }^{F M H}$ and $c_{\alpha, \max }^{F M H}$ are the lower and upper limit of fuel consumption of material handling depending on the weight of loading and $q_{\alpha m a x}^{M H}$ is the upper limit of the material handling weight.

The third parameter of the evaluation is the emission, which can be calculated depending on the fuel consumption:

$$
E^{r}=E_{\text {TRANS }}^{r}\left(l, v, c_{\alpha, \beta}^{F T}\right)+E_{M H}^{r}\left(c_{\alpha, \beta}^{F M H}\right)
$$

where $E^{r}$ is the total emission in the time span of the optimization for emission type $r\left(\mathrm{CO}_{2}, \mathrm{NO}_{\mathrm{x}}, \mathrm{CO}\right.$, $\mathrm{HC}, \mathrm{PM}, \mathrm{SO}_{2}$ ).

The emission of the transportation and material handling process can be described by Equations (8) and (9):

$$
\begin{gathered}
E_{\text {TRANS }}^{r}=\sum_{\alpha=1}^{\alpha_{\max }} \sum_{\beta=1}^{\alpha} l\left(p_{y_{x_{\alpha, \beta}^{*}}}, p_{y_{x_{\alpha, \beta}^{*}}}\right) \cdot c_{\alpha, \beta}^{F T} \cdot e_{\alpha, \beta}^{r}\left(c_{\alpha, \beta}^{F T}\right) \\
E_{M H}^{r}=\sum_{\alpha=1}^{\alpha_{\max }} \sum_{\beta=1}^{\alpha} c_{\max }^{\alpha} c_{\alpha, \beta}^{F M H}\left(q_{x_{\alpha, \beta}^{*}}\right) \cdot e_{\alpha, \beta}^{r}\left(c_{\alpha, \beta}^{F M H}\right)
\end{gathered}
$$

Within the frame of this scenario, the following conventional city logistics problem is analyzed and evaluated. There are 25 pick-up and delivery points in the downtown area, where five delivery trucks collect and distribute various types of goods (e.g., package delivery, waste collection). The positions of the delivery points, and weight and loading/unloading time of goods at all pick-up and delivery points are known (see Tables 1 and 2). 
Table 1. Positions of pick-up and delivery points (test data).

\begin{tabular}{|c|c|c|c|c|c|c|c|c|c|c|c|}
\hline \multirow{2}{*}{$\begin{array}{l}\text { PID } \\
\text { ID }^{1}\end{array}$} & \multicolumn{2}{|c|}{ Coordinates } & \multirow{2}{*}{$\begin{array}{l}\text { PID } \\
\text { ID }^{1}\end{array}$} & \multicolumn{2}{|c|}{ Coordinates } & \multirow{2}{*}{$\begin{array}{l}\text { PID } \\
\text { ID }^{1}\end{array}$} & \multicolumn{2}{|c|}{ Coordinates } & \multirow{2}{*}{$\begin{array}{l}\text { PID } \\
\text { ID }^{1}\end{array}$} & \multicolumn{2}{|c|}{ Coordinates } \\
\hline & $x$ & $\mathbf{y}$ & & $x$ & $\mathbf{y}$ & & $\mathbf{x}$ & $\mathbf{y}$ & & $\mathbf{x}$ & $\mathbf{y}$ \\
\hline 1 & 3.745 & 5.905 & 2 & 4.444 & 5.629 & 3 & 5.052 & 5.187 & 4 & 5.532 & 4.608 \\
\hline 5 & 5.852 & 3.928 & 6 & 5.993 & 3.191 & 7 & 5.947 & 2.441 & 8 & 5.715 & 1.725 \\
\hline 9 & 5.313 & 1.091 & 10 & 4.766 & 0.575 & 11 & 4.108 & 0.212 & 12 & 3.381 & 0.024 \\
\hline 13 & 2.628 & 0.023 & 14 & 1.901 & 0.208 & 15 & 1.241 & 0.569 & 16 & 0.692 & 1.083 \\
\hline 17 & 0.288 & 1.716 & 18 & 0.054 & 2.431 & 19 & 0.005 & 3.181 & 20 & 0.144 & 3.919 \\
\hline 21 & 0.462 & 4.601 & 22 & 0.941 & 5.181 & 23 & 1.547 & 5.624 & 24 & 2.245 & 5.903 \\
\hline 25 & 2.991 & 5.999 & $\mathrm{REF}^{2}$ & 5.800 & 6.200 & - & - & - & - & - & - \\
\hline
\end{tabular}

${ }^{1}$ PID ID = Pick-up or delivery point identification number. ${ }^{2} \mathrm{REF}=$ Reference point, from where the supply chain process is evaluated.

Table 2. Weight of goods to pick-up or delivery (test data).

\begin{tabular}{cccccccccccccccc}
\hline PID ID $^{\mathbf{1}}$ & $\mathbf{1}$ & $\mathbf{2}$ & $\mathbf{3}$ & $\mathbf{4}$ & $\mathbf{5}$ & $\mathbf{6}$ & $\mathbf{7}$ & $\mathbf{8}$ & $\mathbf{9}$ & $\mathbf{1 0}$ & $\mathbf{1 1}$ & $\mathbf{1 2}$ & $\mathbf{1 3}$ & $\mathbf{1 4}$ & $\mathbf{1 5}$ \\
\hline Weight $^{2}$ & -13 & -23 & -43 & -26 & -65 & -38 & 51 & 31 & 12 & -31 & -12 & 24 & 42 & -23 & 62 \\
LUT $^{3}$ & 1.2 & 1.8 & 1.8 & 3.0 & 2.4 & 2.4 & 1.2 & 3.0 & 2.1 & 2.4 & 3.6 & 1.5 & 2.4 & 6.0 & 3.6 \\
PID ID $^{1}$ & 16 & 17 & 18 & 19 & 20 & 21 & 22 & 23 & 24 & 25 & 26 & 27 & 28 & 29 & 30 \\
Weight $^{2}$ & 27 & 45 & 6 & 56 & -42 & 32 & 34 & 55 & -21 & 20 & 43 & 92 & 34 & 10 & 12 \\
LUT $^{3}$ & 2.4 & 3.0 & 2.1 & 1.8 & 3.0 & 2.4 & 1.2 & 12 & 18 & 6.0 & 3.0 & 2.4 & 2.4 & 2.1 & 18 \\
\hline
\end{tabular}

${ }^{1}$ PID ID $=$ Pick-up or delivery point identification number. ${ }^{2}$ Positive values represent delivery points, negative values represent pick-up points. ${ }^{3}$ Loading/unloading time.

There are five delivery routes within the time span of analysis; the capacity of each delivery truck is $400 \mathrm{LU}$ (loading unit). Each delivery route includes six pick-up or delivery points excluding the reference point. The fuel consumption of the trucks is between 41 and $52 \mathrm{~L} / \mathrm{km}$ depending on the weight of the load, while we are calculating with an average speed of $25 \mathrm{~km} / \mathrm{h}$ in the downtown area. The loading and unloading operations are processed by truck-mounted cranes, which have an energy consumption between 25 and $37 \mathrm{~L} /$ loading per hour, depending on the weight of loading.

The pick-up and delivery routes are optimized by each service provider without any cooperation. It means that, within the frame of this scenario, there is no further optimization performed; the results of the analysis of this scenario are used as reference parameters for the later optimization.

As an example, the calculated parameters regarding transportation time, fuel consumption, and emission of route 1 are shown in Figures 3 and 4 . The first service provider is a municipal waste collection provider using a garbage collection truck. It means that its route is a simple collection route with pick-up points. Its collection route is $19.04 \mathrm{~km}$, and the total collection time is $0.97 \mathrm{~h}$, while the energy consumption is $12.48 \mathrm{~L}$ fuel (see Figure 2).
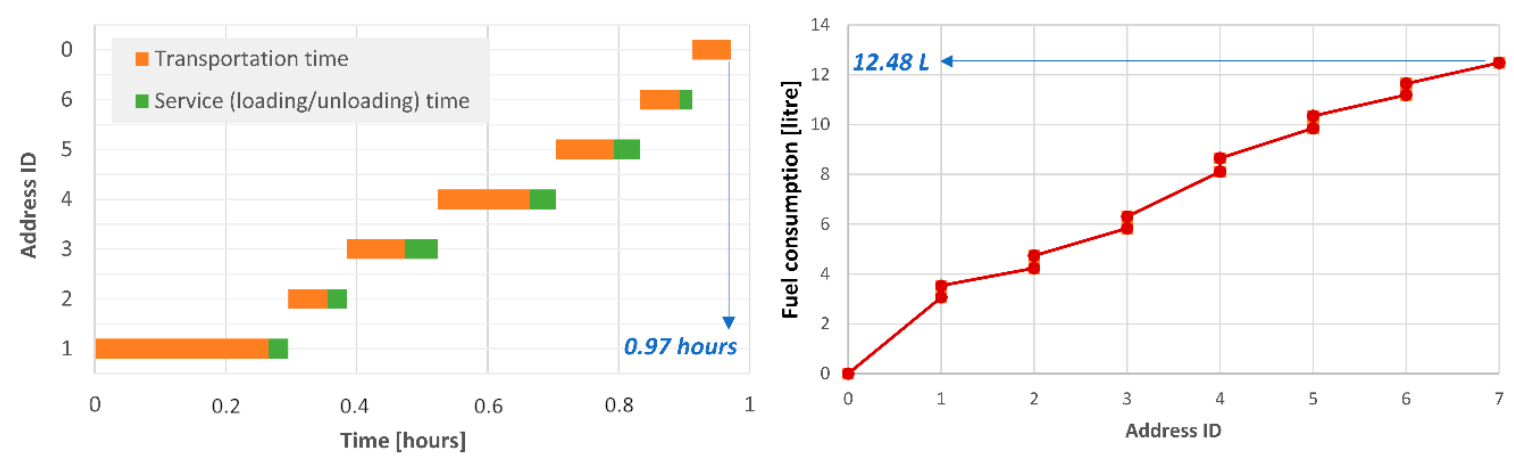

Figure 3. Total transportation time and energy consumption of route 1 in scenario 1. 

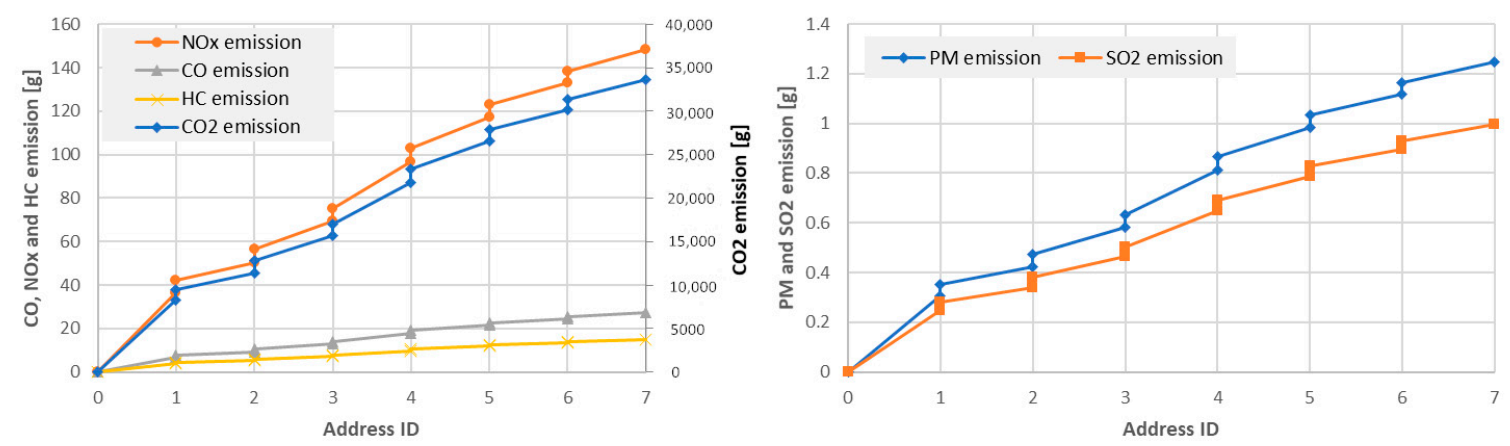

Figure 4. Emission of garbage collection truck in scenario 1.

The emission of diesel consumption can be calculated by [64], as shown in Figure 5. In the case of the first collection route, the $\mathrm{CO}_{2}$ emission is $33,624 \mathrm{~g}$, the $\mathrm{NO}_{\mathrm{x}}$ emission is $148 \mathrm{~g}$, the $\mathrm{CO}$ emission is $37.5 \mathrm{~g}$, the $\mathrm{HC}$ emission is $14.9 \mathrm{~g}$, the $\mathrm{PM}$ emission is $1.25 \mathrm{~g}$, and the $\mathrm{SO}_{2}$ emission is $0.99 \mathrm{~g}$.
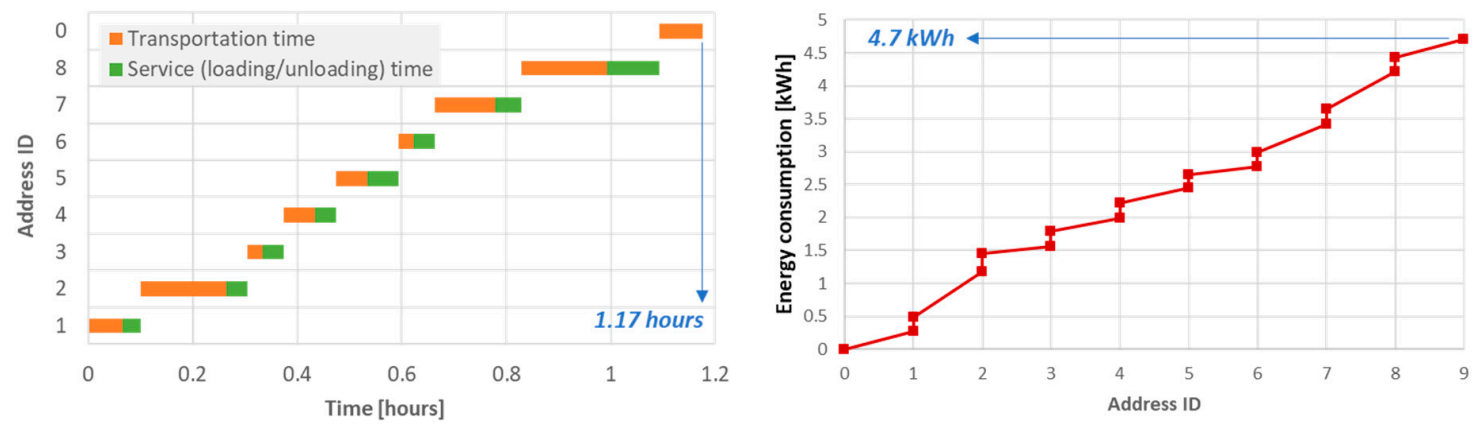

Figure 5. Total transportation time and energy consumption of e-vehicle A in Scenario 2.

The values of the parameters calculated for the other four routes (route 2-5) and the summarized values for Scenario 1 are shown in Table 3. Figures A1 and A2 show the detailed reference parameters.

Table 3. Reference parameters were calculated in Scenario 1.

\begin{tabular}{|c|c|c|c|c|c|c|c|c|c|c|c|c|c|}
\hline \multirow{2}{*}{ Route ID } & \multicolumn{3}{|c|}{ Time } & \multirow{2}{*}{ DIS $^{3}$} & \multicolumn{3}{|c|}{ Fuel Consumption } & \multicolumn{6}{|c|}{ Emission $^{4}$} \\
\hline & TR $^{1}$ & $\mathbf{M}^{2}$ & Total & & $\mathrm{TR}^{1}$ & $\mathbf{M}^{2}$ & Total & $\mathrm{CO}_{2}$ & $\mathrm{NO}_{\mathrm{x}}$ & $\mathrm{CO}$ & HC & PM & $\mathrm{SO}_{2}$ \\
\hline 1 & 0.76 & 0.21 & 0.97 & . & 9.56 & 2.92 & 48 & 33,624 & 148 & 37.5 & 14.9 & 1.25 & 0.99 \\
\hline 2 & 0.75 & 0 . & 0.9 & 8.9 & 9.0 & 2.3 & 11.38 & 30,656 & 13 & 25.0 & 13.6 & 1.13 & 0.91 \\
\hline 3 & 0.77 & 0.33 & 1.10 & 19.41 & 9.82 & 2.18 & 12.00 & 32,354 & 143 & 26.4 & 14.4 & 1.20 & 0.96 \\
\hline 4 & 0.77 & 0.64 & 1.41 & 19.41 & 9.84 & 2.27 & 12.11 & 32,637 & 144 & 26.6 & 14.5 & 1.21 & 0.96 \\
\hline 5 & 0.83 & 0.56 & 1.39 & 20.87 & 10.68 & 2.08 & 12.76 & 34,382 & 152 & 28.1 & 15.3 & 1.27 & 1.02 \\
\hline Total & 3.88 & 1.97 & 5.85 & 97.65 & 48.93 & 11.80 & 60.73 & 163,653 & 722 & 143.6 & 72.7 & 6.06 & 4.84 \\
\hline
\end{tabular}

${ }^{1} \mathrm{TR}=$ Transportation time [hours]. ${ }^{2} \mathrm{M}=$ Materials handling time [hours] (loading/unloading). ${ }^{3}$ DIS $=$ Distance $[\mathrm{km}] .{ }^{4}$ Emission $[\mathrm{g}]$.

Within the frame of the next chapter, the improved city logistics system regarding the collection and distribution of goods such as communal waste, package delivery, or supply of warehouses and shops is described. The above-mentioned parameters will be used as reference parameters to evaluate the new multi-echelon cyber-physical city logistics system, including energy-efficient and environmentally friendly transportation, and material handling solutions. The results of the optimization will be validated by comparing the parameters of the new system with the reference parameters of the conventional system. 


\section{Model of Multi-Echelon Collection and Distribution System in Downtown Areas Based on E-Vehicle Transportation}

Within the frame of this scenario, the following parameters are taken into consideration as input parameters of the optimization task regarding the city area, including locations and tasks: location of pick-up and delivery points, the weight of pick-up and delivery tasks, upper and lower time limits for pick-up and delivery tasks. The following input parameters are linked to the logistics center: the capacity of loading devices, warehouse capacity, location of warehouses, available resources for transportation and materials handling, specific emission, and energy consumption of resources. These parameters are extensively discussed after the equations.

Within the frame of Scenario 2, we use the evaluation functions of Scenario 1 as objective functions. The first objective function is the minimization of the total length of transportation routes which can be based on Equation (1):

$$
L=\sum_{\alpha=1}^{\alpha_{\max }} \sum_{\beta=1}^{\alpha} l\left(p_{y_{x_{\alpha, \beta}}}, p_{y_{x_{\alpha, \beta+1}}}\right) \rightarrow \min .
$$

where $x_{\alpha, \beta}$ is the decision variable of the optimization problem.

The second objective function is the minimization of the fuel consumption, which can be given like Equation (2) by

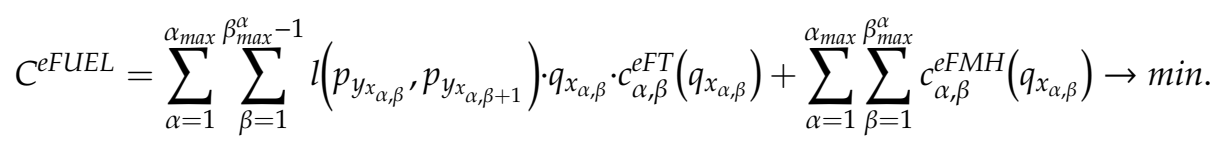

where $C^{e F U E L}$ is the energy consumption of e-trucks and micro-mobility vehicles in $\mathrm{kWh}$.

The specific fuel consumption can be calculated by Equations (2) and (6). The third objective function is the minimization of $\mathrm{CO}_{2}, \mathrm{NO}_{\mathrm{x}}, \mathrm{CO}, \mathrm{HC}, \mathrm{PM}$, and $\mathrm{SO}_{2}$ emission, which can be written like Equation (7):

$$
E^{r}=\sum_{\alpha=1}^{\alpha_{\max }} \sum_{\beta=1}^{\alpha} \beta_{\max }^{-1} l\left(p_{y_{x_{\alpha, \beta}}}, p_{y_{x_{\alpha, \beta}}}\right) \cdot c_{\alpha, \beta}^{e F T} \cdot e_{\alpha, \beta}^{r}+\sum_{\alpha=1}^{\alpha_{\max } \beta_{\max }^{\alpha}} \sum_{\beta=1}^{c F M H}\left(q_{x_{\alpha, \beta}}\right) \cdot e_{\alpha, \beta}^{r} \rightarrow \min
$$

where $c_{\alpha, \beta}^{e F T}$ is the specific energy consumption of e-trucks and micro-mobility vehicles in $\mathrm{kWh} / \mathrm{LUkm}$ (LUkm = loading unit kilometer) and the emissions depend on the e-fuel consumption:

$$
e_{\alpha, \beta}^{r}=e_{\alpha, \beta}^{r}\left(c_{\alpha, \beta}^{e F T}\right) \text { and } e_{\alpha, \beta}^{r}=e_{\alpha, \beta}^{r}\left(c_{\alpha, \beta}^{e F M H}\right)
$$

It is important to mention the similarity between Equations (1) and (10), Equations (2) and (11), and Equations (7) and (12), but Equations (1), (2) and (7) are evaluation functions, where $x_{\alpha, \beta}^{*}$ is a given parameter, while Equations (10)-(12) are objective functions, where $x_{\alpha, \beta}$ is the decision variable of the optimization problem.

The solutions of the above-mentioned optimization problem are limited by some constraints. The first constraint is a capacity-related constraint, which defines that it is not allowed to exceed the loading capacity of the available e-trucks and micro-mobility vehicles (e-cargo bikes, e-cargo scooters or cargo drones):

$$
\forall \alpha: \max \left(q_{x_{\alpha, 1}}, \sum_{\beta=1}^{2} q_{x_{\alpha, \beta}} \sum_{\beta=1}^{3} q_{x_{\alpha, \beta}}, \cdots \sum_{\beta=1}^{\beta_{\max }^{\alpha}} q_{x_{\alpha, \beta}}\right) \leq Q_{\alpha}^{T \max }
$$

where $Q_{\alpha}^{\text {Tmax }}$ is the loading capacity of vehicle $\alpha$. 
The second constraint defines that all pick-up and delivery operations must be performed within a given time span:

$$
\forall k:(\exists \alpha, \beta) \rightarrow x_{\alpha, \beta+1}=k
$$

The third constraint defines that it is not allowed to exceed the capacity of the available loading resource (mounted loading crane or human resource):

$$
\forall \alpha, \beta: x_{\alpha, \beta}>0 \rightarrow q_{x_{\alpha, \beta}} \leq Q_{\alpha}^{\operatorname{Lmax}}
$$

where $Q_{\alpha}^{\operatorname{Lmax}}$ is the capacity of the available loading resource of transportation device $\alpha$.

The fourth constraint defines that it is not allowed to exceed the available energy of e-truck and micro-mobility vehicles:

$$
\forall \alpha: C_{\alpha, \beta_{\max }^{\alpha}}^{e F U E L} \leq C_{\alpha}^{e F U E L \max }
$$

where $C_{\alpha, \beta_{\max }^{\alpha}}^{e F U E L}$ is the energy consumption of e-truck $\alpha$ passing the last pick-up or delivery point assigned to route $\alpha$ and $C_{\alpha}^{\text {EFUELmax }}$ is the available energy of e-truck $\alpha$.

The fifth constraint defines that the utilization of available e-trucks and micro-mobility vehicles must be as equal as possible to increase the flexibility of the system:

$$
\sum_{\alpha=1}^{\alpha_{\max }}\left|\bar{\eta}-\eta_{\alpha}\right| \rightarrow \min
$$

where $\eta_{\alpha}$ is the utilization of the e-truck, which can be written as follows:

$$
\forall \alpha: \eta_{\alpha}=\frac{1}{Q_{\alpha}^{T m a x}} \cdot \max \left(q_{\alpha_{\alpha, 1}}, \sum_{\beta=1}^{2} q_{x_{\alpha, \beta}} \sum_{\beta=1}^{3} q_{\alpha_{\alpha, \beta}}, \cdots \sum_{\beta=1}^{\beta_{\max }^{\alpha}} q_{\alpha_{\alpha, \beta}{ }^{\prime}}\right)
$$

and $\bar{\eta}$ is the average utilization of e-vehicles, which can be calculated by

$$
\bar{\eta}=\frac{1}{\alpha_{\max }} \cdot \sum_{\alpha=1}^{\alpha_{\max }} \eta_{\alpha}
$$

The sixth constraint defines that the pick-up and delivery tasks can be processed only with suitable vehicles:

$$
\forall k: s_{k, \alpha}=0 \rightarrow x_{\alpha, \beta}=0 \text { otherwise } x_{\alpha, \beta} \in(0,1)
$$

where $s_{k, \alpha}$ is the suitability parameter; if $s_{k, \alpha}=1$ then e-vehicle $\alpha$ is suitable to process pick-up or delivery task $k$, otherwise not.

Within the frame of Scenario 2, the following multi-echelon city logistics problem is analyzed and evaluated. There is a logistics center outside the city border and e-vehicles are available to perform pick-up and delivery tasks. The 25 pick-up and delivery points in the downtown area and the 30 pick-up and delivery tasks are the same as in Scenario 1. The positions of the delivery points, the weight and loading/unloading time of goods at each pick-up and delivery points are known (see Tables 1 and 2). Table 4 shows the suitability matrix, which is an assignment matrix among e-vehicles and pick-up or delivery tasks.

Other input parameters of the optimization problem regarding the e-vehicles, like capacity, specific energy consumption, are shown in Table 5.

We have used the Excel evolutive Solver Tool to solve the above described NP-hard optimization problem, which includes the clustering of pick-up and delivery tasks, the assignment of pick-up and delivery tasks to the available and suitable e-vehicles, and the routing of e-vehicles. 
Table 4. Suitability of vehicles to perform pick-up and delivery tasks.

\begin{tabular}{|c|c|c|c|c|c|c|c|c|c|c|c|c|c|c|c|}
\hline PID ID $^{1}$ & 1 & 2 & 3 & 4 & 5 & 6 & 7 & 8 & 9 & 10 & 11 & 12 & 13 & 14 & $\overline{15}$ \\
\hline $\mathrm{GT}^{2}$ & 1 & 1 & 1 & 1 & 1 & 1 & 0 & 0 & 0 & 0 & 0 & 0 & 0 & 0 & 0 \\
\hline e-T A ${ }^{3}$ & 0 & 0 & 0 & 0 & 0 & 0 & 1 & 0 & 1 & 1 & 1 & 0 & 0 & 1 & 1 \\
\hline$e-B^{3}$ & 0 & 0 & 0 & 0 & 0 & 0 & 1 & 1 & 0 & 0 & 0 & 0 & 1 & 0 & 1 \\
\hline $\mathrm{e}-\mathrm{tC}^{3}$ & 0 & 0 & 0 & 0 & 0 & 0 & 0 & 1 & 1 & 1 & 1 & 1 & 1 & 1 & 0 \\
\hline PID ID $^{1}$ & 16 & 17 & 18 & 19 & 20 & 21 & 22 & 23 & 24 & 25 & 26 & 27 & 28 & 29 & 30 \\
\hline $\mathrm{GT}^{2}$ & 0 & 0 & 0 & 0 & 0 & 0 & 0 & 0 & 0 & 0 & 0 & 0 & 0 & 0 & 0 \\
\hline e-T A ${ }^{3}$ & 1 & 1 & 0 & 0 & 1 & 1 & 0 & 0 & 0 & 1 & 0 & 1 & 1 & 0 & 0 \\
\hline e-t B ${ }^{3}$ & 1 & 0 & 1 & 1 & 0 & 1 & 1 & 1 & 1 & 0 & 0 & 0 & 0 & 1 & 1 \\
\hline $\mathrm{e}-\mathrm{t} C^{3}$ & 0 & 0 & 1 & 1 & 1 & 0 & 1 & 1 & 1 & 1 & 1 & 0 & 1 & 1 & 1 \\
\hline
\end{tabular}

1 PID ID = Pick-up or delivery point identification number. ${ }^{2} \mathrm{GT}=$ garbage truck. ${ }^{3} \mathrm{e}-\mathrm{T}=$ e-truck for general transportation purposes.

Table 5. Energy consumption and capacity parameters of e-vehicles in Scenario 2.

\begin{tabular}{ccccccc}
\hline \multirow{2}{*}{ Vehicle } & \multicolumn{2}{c}{$\begin{array}{c}\text { Energy Consumption } \\
\text { Transportation [kWh] }\end{array}$} & \multicolumn{2}{c}{$\begin{array}{c}\text { Energy Consumption } \\
\text { Loading/Unloading [kWh] }\end{array}$} & \multicolumn{2}{c}{ Capacity [LU] } \\
\cline { 2 - 7 } & $\min$ & $\max$ & $\min$ & $\max$ & TRANS $^{\mathbf{1}}$ & MH $^{\mathbf{2}}$ \\
\hline & 20 & 41 & 14 & 22 & 300 & 80 \\
GT $^{3}$ & 11 & 18 & 12 & 17 & 350 & 100 \\
e-T A & 12 & 19 & 11 & 16 & 380 & 70 \\
e-t B & 9 & 18 & 10 & 15 & 240 & 60 \\
e-t C & & 9 & &
\end{tabular}

${ }^{1}$ TRANS $=\overline{\text { Transportation. }{ }^{2} \mathrm{MH}=\text { material handling, loading, unloading. }{ }^{3} \mathrm{GT}=\text { garbage truck. }{ }^{4} \mathrm{e}-\mathrm{T}}=\mathrm{e}$-truck for general transportation purposes.

The evolutive option of the Excel Solver represents a robust algorithm to solve NP-hard optimization problems. The evolutive option of the Solver is based on an evolutionary method, like the genetic algorithm or particle swarm optimization methods. The Solver starts with a random population and uses crossover and mutation operators to avoid local optimum, in order to find the near-global optimum solution of the NP-hard optimization problem [65]. Table 6 shows the results of the numerical experiments for algorithm evaluation with various benchmark functions [66].

Table 6. Performance analysis of the Excel evolutive Solver: error values in the case of six benchmark functions after various iteration steps.

\begin{tabular}{cccc}
\hline \multirow{2}{*}{ Benchmark Function [66] } & \multicolumn{3}{c}{ Iteration Steps } \\
\cline { 2 - 4 } Qing function & $\mathbf{2 0}$ & $\mathbf{5 0}$ & $\mathbf{1 0 0}$ \\
$f(x)=\sum_{i=1}^{n}\left(x^{2}-i\right)^{2}$ & $2.72 \times 10^{-6}$ & $1.55 \times 10^{-7}$ & $7.27 \times 10^{-9}$ \\
Schwefel 2.22 function & & \\
$f(x)=\sum_{i=1}^{n}\left|x_{i}\right|+\prod_{i=1}^{n}\left|x_{i}\right|$ & $1.57 \times 10^{-5}$ & $6.43 \times 10^{-8}$ & $1.34 \times 10^{-8}$ \\
Alpine $N^{2}$ function & & & \\
$f(x)=\prod_{i=1}^{n} \sqrt{x_{i}} \cdot \sin \left(x_{i}\right)$ & $4.92 \times 10^{-6}$ & $2.11 \times 10^{-7}$ & $6.72 \times 10^{-9}$ \\
Powell Sum function & & & \\
$f(x)=\sum_{i=1}^{n}\left|x_{i}\right|^{i+1}$ & $5.06 \times 10^{-5}$ & $9.17 \times 10^{-6}$ & $8.72 \times 10^{-7}$ \\
Ridge function & & & \\
$f(x)=x_{1}+d \cdot\left(\sum_{i=2}^{n} x_{i}^{2}\right)^{\alpha}$ & $3.61 \times 10^{-6}$ & $1.50 \times 10^{-7}$ & $4.47 \times 10^{-8}$ \\
Rastrigin function & & & \\
$10 \cdot n+\sum_{i=1}^{n}\left(x_{i}^{2}-10 \cdot \cos \left(2 \cdot \pi \cdot x_{i}\right)\right)$ & $6.22 \times 10^{-5}$ & $7.15 \times 10^{-5}$ & $3.28 \times 10^{-6}$ \\
\hline$f(x)=$ & & & \\
\hline
\end{tabular}

As the below described computational results and the comparison with the reference parameters of Scenario 1 show, it was not necessary to develop a special heuristic or metaheuristic algorithm to solve the problem. 
As an example, the parameters of the optimized system regarding transportation time, fuel consumption, and emission of route 1 are shown in Figures 5 and 6 . The route sum of e-vehicle A is $19.28 \mathrm{~km}$, the total time sum is $1.17 \mathrm{~h}$, while the energy consumption is $4.7 \mathrm{kWh}$ (see Figure 5).
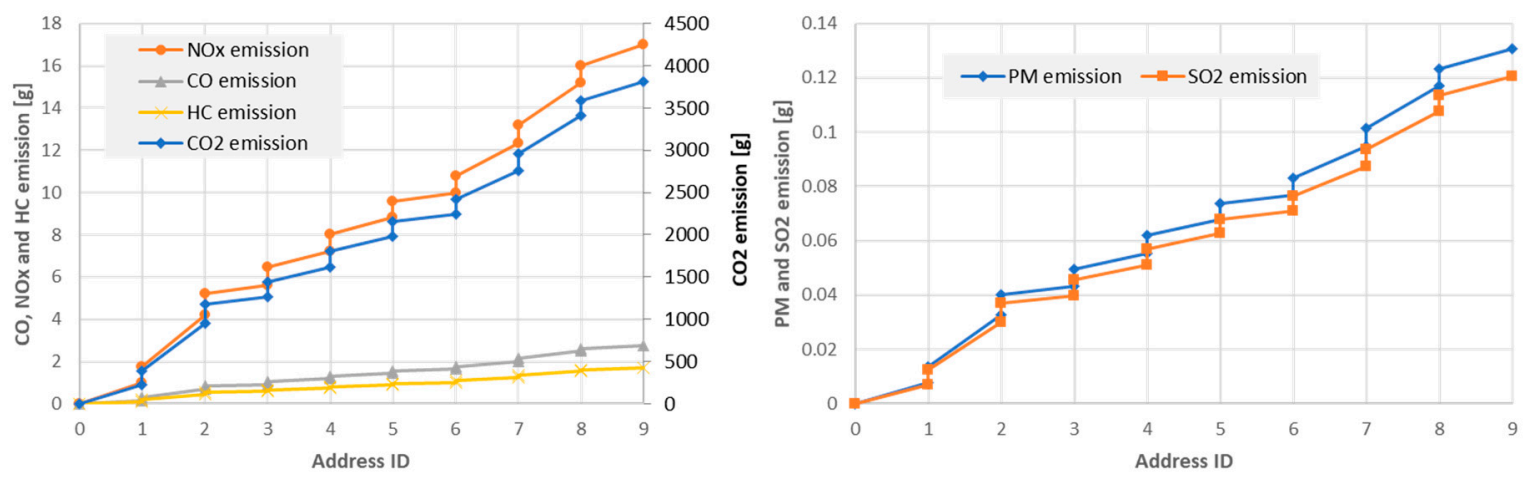

Figure 6. Emission of e-vehicle B in Scenario 2. The energy generation source is coal and the peak loads are met by natural gas turbines.

The virtual emission of energy consumption depending on the energy generation source can be calculated by [67]. We have compared two extreme cases. In the first case, the energy generation source is coal, and peak loads are met by natural gas turbines (see Figure 6).

In the case of e-vehicle $\mathrm{A}$, the $\mathrm{CO}_{2}$ emission is $3810 \mathrm{~g}$, the $\mathrm{NO}_{\mathrm{x}}$ emission is $16.99 \mathrm{~g}$, the $\mathrm{CO}$ emission is $2.77 \mathrm{~g}$, the $\mathrm{HC}$ emission is $1.72 \mathrm{~g}$, the $\mathrm{PM}$ emission is $0.13 \mathrm{~g}$, and the $\mathrm{SO}_{2}$ emission is $0.12 \mathrm{~g}$. The emission reduction is significant because more pick-up and delivery points were processed with this e-vehicle than in one route of Scenario 1. It would be expected that, in this case, the emissions would not be better than for diesel trucks, but in this case, two major influencing factors must be taken into consideration. The first one is the energy generation source. It does not have a significant impact on emission reduction. The second one is the structure of the supply chain; in the case of the multi-level solution, the total energy consumption of vehicles can be decreased, which leads to an emission reduction.

In the second case, the energy generation source is hydro. In the hydro-based energy generation, the $\mathrm{CO}_{2}$ emission is $122 \mathrm{~g}$, the $\mathrm{NO}_{\mathrm{x}}$ emission is $0.56 \mathrm{~g}$, the $\mathrm{CO}$ emission is $0.1 \mathrm{~g}$, the $\mathrm{HC}$ emission is $0.06 \mathrm{~g}$, the $\mathrm{PM}$ emission is $0.0047 \mathrm{~g}$, and the $\mathrm{SO}_{2}$ emission is $0.002 \mathrm{~g}$ (see Figure 7). In this case, not only the multi-level structure of the supply chain, but also the energy generation source, has a great impact on the virtual emission reduction.
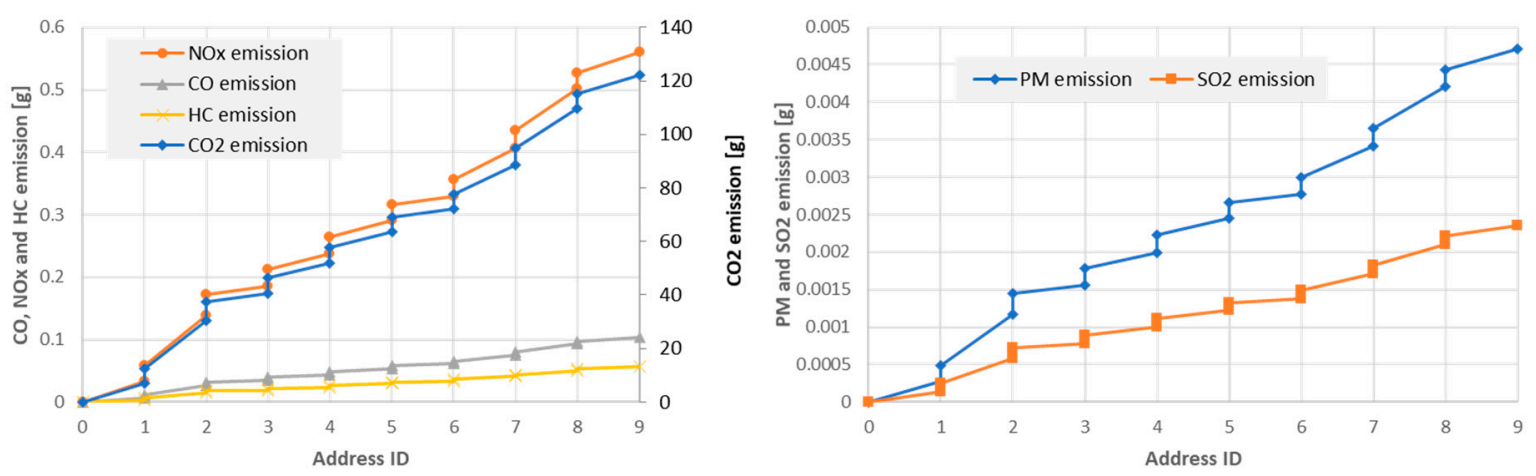

Figure 7. Emission of e-vehicle B in Scenario 2. The energy generation source is hydro. 
Figure 8 shows the summarized results of the optimization. Four pick-up and delivery routes were organized, depending on the capacity of e-vehicles, the suitability of e-vehicles and loading equipment, the weight of pick-up and delivery tasks, the position of pick-up, and delivery points.
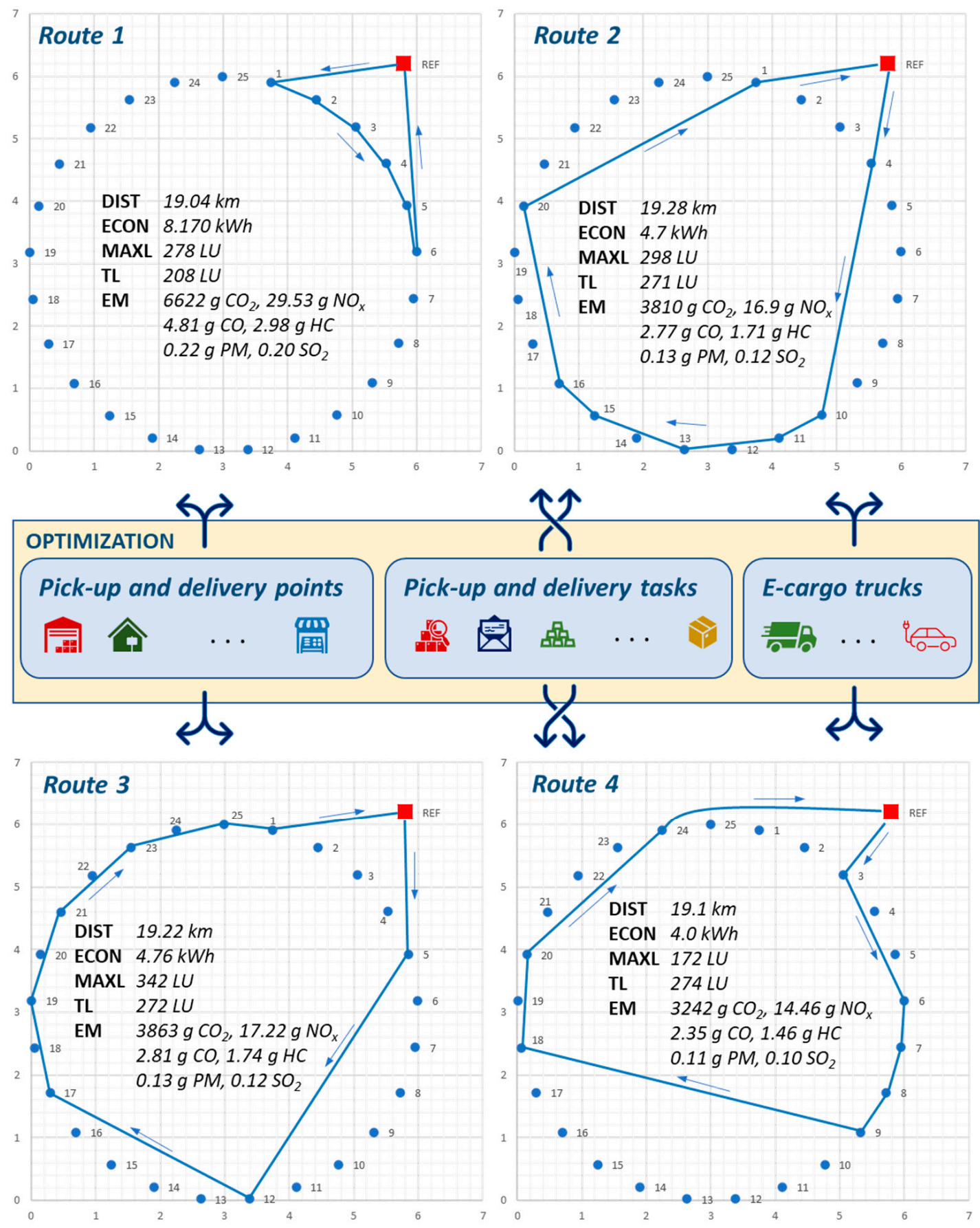

Figure 8. Results of the optimization in Scenario 2. (DIST = Total distance of the route, ECON = energy consumption of e-vehicles, MAX = maximum loading of the e-vehicle, TL $=$ total loading transported, $\mathrm{EM}=$ emission). The energy generation source is coal and natural gas turbine (in the case of peaks).

The waste collection route was not changed, because municipal waste collection needs special garbage collection vehicles. This means that the collection of municipal waste cannot be integrated with other collection or distribution processes. The remaining 24 pick-up and delivery tasks were organized into three additional routes. The comparison of the conventional city-logistics solution 
and the multi-echelon, e-vehicle based system shows that the transformation of a conventional city logistics solution into a multi-echelon supply based on a logistics center outside of the city border (or downtown area) and the application of e-trucks and other e-vehicles can significantly reduce energy consumption and the emission.

The transformation of a conventional city logistics solution into the suggested e-vehicle-based multi-echelon system led to a decrease in the required time, transportation distances, energy consumption, and emission. Depending on the energy generation source, it is possible to reduce the emission with significant values. As Table 7 shows, in the case of coal-based e-energy generation (peaks are based on natural gas), this emission reduction is about $90 \%$, but in the case of photovoltaic, wind, or water source of energy, the reduction can be increased compared with fuel-based emission. Figures $\mathrm{A} 3$ and $\mathrm{A} 4$ show the detailed parameters of the optimized routes.

Table 7. Comparison of conventional city logistics solution and multi-echelon, e-vehicle-based system.

\begin{tabular}{|c|c|c|c|c|c|c|c|c|}
\hline \multirow{2}{*}{ Route ID } & \multirow{2}{*}{ Time } & \multirow{2}{*}{ DIS $^{3}$} & \multicolumn{6}{|c|}{ Emission $^{4}$} \\
\hline & & & $\mathrm{CO}_{2}$ & $\mathrm{NO}_{\mathbf{x}}$ & $\mathrm{CO}$ & $\mathrm{HC}$ & PM & $\mathrm{SO}_{2}$ \\
\hline \multicolumn{9}{|l|}{ Scenario $\mathbf{1}^{1}$} \\
\hline Total & 5.85 & 97.65 & 163,653 & 722 & 143.6 & 72.7 & 6.06 & 4.84 \\
\hline $\mathrm{PPT}^{2}$ & 0.195 & 3.255 & 5455.1 & 24 & 4.78 & 2.42 & 0.2 & 0.16 \\
\hline Scenario 2 & \multicolumn{8}{|c|}{ Hydro } \\
\hline Garbage $^{5}$ & 1.02 & 19.04 & 212 & 0.97 & 0.18 & 0.09 & 0.008 & 0.004 \\
\hline eVehicle A & 1.17 & 19.28 & 122 & 0.55 & 0.10 & 0.05 & 0.004 & 0.002 \\
\hline eVehicle B & 1.17 & 19.22 & 123 & 0.57 & 0.10 & 0.05 & 0.004 & 0.002 \\
\hline eVehicle C & 1.16 & 19.1 & 104 & 0.47 & 0.08 & 0.04 & 0.004 & 0.002 \\
\hline Total & 4.52 & 76.64 & 561 & 2.56 & 0.46 & 0.23 & 0.02 & 0.001 \\
\hline $\mathrm{PPT}^{2}$ & 0.15 & 2.55 & 18.7 & 0.085 & 0.015 & 0.007 & $<0.001$ & $<0.001$ \\
\hline Scenario 2 & \multicolumn{8}{|c|}{ Coal and Hydro (Peak) } \\
\hline Garbage $^{5}$ & 1.02 & 19.04 & 6622 & 29.53 & 4.81 & 2.98 & 0.22 & 0.20 \\
\hline eVehicle A & 1.17 & 19.28 & 3810 & 16.99 & 2.77 & 1.71 & 0.13 & 0.12 \\
\hline eVehicle B & 1.17 & 19.22 & 3863 & 17.22 & 2.81 & 1.74 & 0.13 & 0.12 \\
\hline eVehicle C & 1.16 & 19.1 & 3242 & 14.46 & 2.35 & 1.46 & 0.11 & 0.10 \\
\hline Total & 4.52 & 76.64 & 17,537 & 78.2 & 12.74 & 7.89 & 0.59 & 0.54 \\
\hline $\mathrm{PPT}^{2}$ & 0.15 & 2.55 & 584.56 & 2.60 & 0.42 & 0.26 & 0.02 & 0.02 \\
\hline
\end{tabular}

${ }^{1}$ See Table $3 .{ }^{2}$ PPT $=$ Parameter per pick-up or delivery task. ${ }^{3}$ DIS = Distance $[\mathrm{km}] .{ }^{4}$ Emission in $[\mathrm{g}] .{ }^{5}$ Garbage collection route in Scenario 2.

The next scenario shows the solution of a real-world size problem in the shopping area of the Miskolc City Centre West, where 35 last-mile objects (banks, stores, supermarkets, pharmacies, restaurants) were taken into consideration. We have compared the conventional material supply (supply chain) solution and the e-vehicle based solution in this area. As Table 8 shows, the e-vehicle-based solution resulted in a $92 \%$ emission reduction (average). Figures A5-A7 in Appendix E show the optimized routes of the e-vehicle-based solution.

The upgrade of the conventional fleet to e-vehicles has a great impact on energy demand, sustainability, and the environment. It means that the future of city logistics is the use of e-vehicles and the transformation of conventional solutions into cyber-physical systems using Industry 4.0 technologies. 
Table 8. Emission comparison of conventional and e-vehicle-based solutions in the case of a real-world size problem $[\mathrm{g}]$.

\begin{tabular}{|c|c|c|c|c|c|c|}
\hline Route ID & $\mathrm{CO}_{2}$ & $\mathrm{NO}_{\mathbf{x}}$ & $\mathrm{CO}$ & $\mathrm{HC}$ & PM & $\mathrm{SO}_{2}$ \\
\hline \multicolumn{7}{|l|}{ e-vehicle-based solution } \\
\hline \multicolumn{7}{|l|}{ Route A } \\
\hline Sberbank & 1349.296 & 0.0432 & 1.1302 & 0.6165 & 6.0191 & 0.0513 \\
\hline Adria Travel Agency & 311.376 & 0.0099 & 0.2608 & 0.0422 & 1.3890 & 0.0118 \\
\hline Raiffeisen Bank & 311.376 & 0.0099 & 0.2608 & 0.1422 & 1.3890 & 0.0118 \\
\hline Uniqua & 415.168 & 0.0133 & 0.3477 & 0.1896 & 1.8520 & 0.0158 \\
\hline Tiszacash & 103.792 & 0.0033 & 0.0869 & 0.0474 & 0.4630 & 0.0039 \\
\hline Post Office & 1245.504 & 0.0399 & 1.0433 & 0.5690 & 5.5560 & 0.0474 \\
\hline Tax Office & 51.896 & 0.0160 & 0.0434 & 0.0237 & 0.2315 & 0.0019 \\
\hline Ibusz Travel Agency & 1037.92 & 0.0332 & 0.8694 & 0.4742 & 4.6300 & 0.0390 \\
\hline Hub & 4826.328 & 0.1547 & 4.0428 & 2.2052 & 21.5298 & 0.1837 \\
\hline Total emission of Route 1 & 9652.656 & 0.3095 & 8.0857 & 4.4104 & 43.0597 & 0.3670 \\
\hline \multicolumn{7}{|l|}{ Route B } \\
\hline Finchi Restaurant & 1037.92 & 0.03328 & 0.86944 & 0.47424 & 4.63008 & 0.03952 \\
\hline Calipso Restaurant & 103.79 & 0.00332 & 0.08694 & 0.04742 & 0.46300 & 0.00395 \\
\hline Petit Cafe & 726.54 & 0.02329 & 0.60860 & 0.33196 & 3.24105 & 0.02766 \\
\hline Vendelin Restaurant & 1089.81 & 0.03494 & 0.91291 & 0.49795 & 4.86158 & 0.04149 \\
\hline Spar Supermarket & 51.89 & 0.00166 & 0.04347 & 0.02371 & 0.23150 & 0.00197 \\
\hline Hotel Pannonia & 726.54 & 0.02329 & 0.60860 & 0.33196 & 3.24105 & 0.02766 \\
\hline Wok King & 934.12 & 0.02995 & 0.78249 & 0.42681 & 4.16707 & 0.03556 \\
\hline Coffeshop Company & 986.02 & 0.03161 & 0.82596 & 0.45052 & 4.39857 & 0.03754 \\
\hline TESCO Express & 259.48 & 0.00832 & 0.21736 & 0.11856 & 1.15752 & 0.00988 \\
\hline Hub & 4878.22 & 0.15641 & 4.08636 & 2.22892 & 21.76136 & 0.18574 \\
\hline Total emission of Route 2 & $10,794.36$ & 0.34611 & 9.04217 & 4.93209 & 48.15283 & 0.41100 \\
\hline \multicolumn{7}{|l|}{ Route C } \\
\hline Samsung Store & 1556.8 & 0.0499 & 1.3041 & 0.7113 & 6.9451 & 0.0592 \\
\hline Hollóházi Porcelan Store & 1764.4 & 0.0565 & 1.4780 & 0.8062 & 7.8711 & 0.0671 \\
\hline Szinva Optic & 1816.3 & 0.0582 & 1.5215 & 0.8299 & 8.1026 & 0.0691 \\
\hline Erzsébet Privat Hospital & 3061.8 & 0.0981 & 2.5648 & 1.3990 & 13.6587 & 0.1165 \\
\hline Barber Shop & 4099.7 & 0.1314 & 3.4342 & 1.8732 & 18.2888 & 0.1561 \\
\hline Viva Travel & 4151.6 & 0.1331 & 3.4777 & 1.8969 & 18.5203 & 0.1586 \\
\hline Budo Sport & 4203.5 & 0.1347 & 3.5212 & 1.9206 & 18.7518 & 0.1600 \\
\hline Miskolc Gallery & 5708.5 & 0.1830 & 4.7819 & 2.6083 & 25.4654 & 0.2173 \\
\hline Karikagyû́rú Jewellery & 6642.6 & 0.2129 & 5.5644 & 3.0351 & 29.6325 & 0.2529 \\
\hline Metropol Supermarket & 7473.0 & 0.2396 & 6.2599 & 3.4145 & 33.3365 & 0.2845 \\
\hline Telekom Shop & 8303.3 & 0.2662 & 6.9555 & 3.7939 & 37.0406 & 0.3161 \\
\hline BENU Pharmacy & 8459.0 & 0.2712 & 7.0859 & 3.8650 & 37.7351 & 0.3220 \\
\hline Vision Express & 8666.6 & 0.2778 & 7.2598 & 3.9599 & 38.6611 & 0.3299 \\
\hline Museum of Theatres & 9496.9 & 0.3045 & 7.9553 & 4.3392 & 42.3652 & 0.3616 \\
\hline National Theatre & 9860.2 & 0.3161 & 8.2596 & 4.5052 & 43.9857 & 0.3754 \\
\hline Rossmann Drogerie & $10,275.4$ & 0.3294 & 8.6074 & 4.6949 & 45.8377 & 0.3912 \\
\hline Pátria Pharmacy & $10,690.5$ & 0.3427 & 8.9552 & 4.8846 & 47.6898 & 0.4070 \\
\hline X-Train Clothing & $11,157.6$ & 0.3577 & 9.3464 & 5.0980 & 49.7733 & 0.4248 \\
\hline Hub & $22,315.2$ & 0.7155 & 18.6929 & 10.1961 & 99.5467 & 0.8496 \\
\hline Total emission of Route 3 & $139,704.0$ & 4.4794 & 117.026 & 63.8327 & 623.2087 & 5.3193 \\
\hline Total emission & $160,151.0$ & 5.1351 & 134.154 & 73.1752 & 714.4213 & 6.0979 \\
\hline \multicolumn{7}{|l|}{ Conventional solution } \\
\hline Total emission & $1,869,618$ & 56.8921 & 1564.53 & 853.382 & 8462.708 & 71.1152 \\
\hline Emission reduction [\%] & 8.566 & 9.062 & 8.574 & 8.547 & 8.442 & 8.574 \\
\hline
\end{tabular}

\section{Conclusions}

The adoption of e-vehicles in city logistics solutions appears to be progressing faster than expected $[68,69]$. City logistics processes based on e-vehicles lead to decreased fuel consumption and emission, while the availability and flexibility can be increased. Energy efficiency, sustainability, and emission reduction have been extensively researched in all fields of logistics. Service processes are also discussed, but many of the articles are focusing on manufacturing-related systems. In order to start filling this gap, this work has developed a methodology to analyze existing conventional city logistics solutions and optimize new e-vehicle-based multi-echelon systems. The model includes a wide range of objective functions, like the minimization of transportation distance, energy consumption, and the emission of greenhouse gases, while various constraints like the capacity of resources, service level, availability and suitability of material handling resources, and available energy in high voltage batteries 
or fuel cells are taken into consideration. The described methodology shows that the transformation of conventional city logistics solutions into an e-vehicle based multi-echelon supply chain significantly decreases energy consumption and emission, while service level and flexibility are likely to be increased. Depending on the source of electric energy generation, different emission reduction can be realized. The article shows that by using oil-based energy generation sources, $88 \%$ emission reduction can be reached. Table A2 shows these reduced rates in the case of the same scenario taking other energy generation sources, like coal, photovoltaic, wind, or water into account.

As a managerial impact, we would like to mention that the application of the above-described methodology can support managerial decisions regarding the logistics center, the adoption of various e-vehicles, and micro-mobility vehicles, or the operation strategy of the whole supply chain. We can summarize the conclusions and research implications as follows:

- The development of new city logistics solutions must be based on the performance evaluation of available conventional systems. We developed a new methodology for the evaluation of conventional city logistics solutions to calculate time-, distance-, energy consumption-, and emission-related performance parameters.

- Designing and operating sustainable city logistics systems are great challenges for researchers because of the complexity of city logistics solutions, especially in the case of cyber-physical systems, led to NP-hard optimization problems, where the application of heuristic and metaheuristic solutions is unavoidable. We developed a mathematical model to support the design and optimization of a multi-echelon city logistics solution. The model takes capacity, timeliness, suitability, availability, and energy-related constraints into consideration.

- The comparison and the computational results of conventional and multi-echelon e-vehicle-based city logistics solutions show that the multi-level supply chain and the application of e-vehicles have a great impact on costs, energy efficiency, emission, and service level.

- The emission rates are based on well-to-wheel analysis, where the production and transportation of primary fuel, production and transportation, and road fuel are taken into consideration [70].

A further study of the proposed work would be the integration of the above-mentioned methodology with a digital twin solution. Another research direction is to develop a more robust and faster tailored computational method and algorithm to solve a real city logistics network. By using the digital twin process, it would be possible to extend the optimization range of the proposed model to real-time scheduling of new pick-up or delivery tasks into the existing processes. An additional aspect of optimization would be the application of the lean paradigm [71], simulation [72] and heuristic optimization [73], to improve the efficiency of the existing conventional system or the transformed system. The emissions of first mile supply to the hub are not taken into account, because the conventional and e-vehicle based systems are the same from the first mile suppliers to the hub (if the hub is near the check-in point of the downtown area). A potential future research direction is to improve the model with first mile options to create a combined first-mile/last-mile model. The emissions of the hub can also be taken into consideration. The impact of the emission regarding heating, water, air-conditioning, and electricity can be analyzed. Another future research direction is to check our model with the Fiori model [47], which is a complex model for the evaluation of energy consumption of electric freight vehicles in urban pickup/delivery operations.

Author Contributions: Conceptualization, T.B.; methodology, M.Z.A.; software, M.Z.A.; validation, M.Z.A. and T.B.; formal analysis, M.Z.A. and T.B.; investigation, M.Z.A. and T.B.; resources, M.Z.A. and T.B.; data curation, M.Z.A. and T.B.; writing-original draft preparation, M.Z.A. and T.B.; writing—review and editing, M.Z.A. and T.B.; visualization, M.Z.A. and T.B.; supervision, T.B.; project administration, T.B.; funding acquisition, T.B. All authors have read and agreed to the published version of the manuscript.

Funding: The described article was carried out as part of the EFOP-3.6.1-16-2016-00011 “Younger and Renewing University-Innovative Knowledge City—institutional development of the University of Miskolc aiming at intelligent specialisation" project implemented in the framework of the Szechenyi 2020 program. The realization of this project is supported by the European Union, co-financed by the European Social Fund. 
Conflicts of Interest: The authors declare no conflict of interest.

\section{Appendix A}

Table A1 shows the nomenclature used in the mathematical models.

Table A1. Nomenclature used in the mathematical model.

\begin{tabular}{|c|c|}
\hline Symbol & Definition \\
\hline \multicolumn{2}{|r|}{ Parameters } \\
\hline$L$ & the total length of the transportation routes within the time span of optimization \\
\hline$\alpha$ & the number of delivery trucks \\
\hline$\beta_{\max }^{\alpha}$ & the number of pick-up and delivery points assigned to collection route $\alpha$ \\
\hline$x_{\alpha . \beta}^{*}$ & the ID number of pick-up and delivery task assigned to route $\alpha$ as pick-up or delivery task $\beta$ \\
\hline$y_{x_{\alpha \beta \beta}^{*}}^{*}$ & the ID of pick-up or delivery point \\
\hline$p_{y_{x_{\alpha, \beta}^{*}}}$ & the position of pick-up or delivery point assigned to route $\alpha$ as pick-up or delivery task $\beta$ \\
\hline$l$ & the length of transportation route as a function of positions of pick-up and delivery points \\
\hline$C_{T}^{F U E L}$ & the fuel consumption of the whole transportation process without material handling (loading and unloading) \\
\hline$c_{\alpha . \beta}^{F T}$ & the specific fuel consumption of transportation \\
\hline$C_{M H}^{F U E L}$ & the fuel consumption of material handling operations at the pick-up and delivery points \\
\hline$c_{\alpha . \beta}^{F M H}$ & the specific fuel consumption regarding material handling operations \\
\hline$v$ & the average speed of the truck \\
\hline$q_{x_{\alpha \cdot \beta}}$ & the pick-up or delivery volume assigned to route $\alpha$ as pick-up or delivery task $\beta$ \\
\hline$c_{\alpha . \min }^{F T}$ and $c_{\alpha . \max }^{F T}$ & the lower and upper limit of fuel consumption of transportation depending on the weight of loading \\
\hline$q_{\alpha \max }^{\text {TRANS }}$ & the upper limit of the loading weight \\
\hline$c_{\alpha . \min }^{F M H}$ and $c_{\alpha . \max }^{F M H}$ & the lower and upper limit of fuel consumption of material handling depending on the weight of loading \\
\hline$q_{\alpha m a x}^{M H}$ & the upper limit of the material handling weight \\
\hline$E^{r}$ & the total emission in the time span of the optimization for emission type $r\left(\mathrm{CO}_{2} . \mathrm{NO}_{\mathrm{x}}\right.$. CO. HC. PM. SO $)$ \\
\hline$x_{\alpha . \beta}$ & the decision variable of the optimization problem \\
\hline$C^{e F U E L}$ & the energy consumption of e-trucks and micro-mobility vehicles in $\mathrm{kWh}$ \\
\hline$c_{\alpha . \beta}^{e F T}$ & the specific energy consumption of e-trucks and micro-mobility vehicles \\
\hline$Q_{\alpha}^{\text {Tmax }}$ & the loading capacity of vehicle $\alpha$ \\
\hline$Q_{\alpha}^{\operatorname{Lmax}}$ & the capacity of the available loading resource of transportation device $\alpha$ \\
\hline$C_{\alpha \cdot \beta_{\max }^{\alpha}}^{e F U E L}$ & the energy consumption of e-truck $\alpha$ passing the last pick-up or delivery point assigned to route $\alpha$ \\
\hline$C_{\alpha}^{e F U E L \max }$ & the available energy of e-truck $\alpha$ \\
\hline$\eta_{\alpha}$ & the utilization of the e-truck \\
\hline $\bar{\eta}$ & the average utilization of e-vehicles \\
\hline$s_{k . \alpha}$ & the suitability parameter \\
\hline \multicolumn{2}{|r|}{ Decision variables } \\
\hline$x_{\alpha . \beta}^{*}$ & $\begin{array}{l}\text { the ID number of pick-up and delivery task assigned to route } \alpha \text { as pick-up or delivery task } \beta \text { in Scenario } 1 \\
\text { (conventional model) }\end{array}$ \\
\hline$y_{x_{\alpha, \beta}^{*}}$ & the ID of pick-up or delivery point \\
\hline$x_{\alpha . \beta}$ & the assignment matrix as a decision variable of the optimization problem in Scenario 2 (e-vehicle based model) \\
\hline
\end{tabular}

\section{Appendix B}

Appendix B includes some analysis details regarding Scenario 1. Figure A1 shows the calculated length of transportation routes and the required times to perform the whole collection/distribution process including transportation and materials handling. 

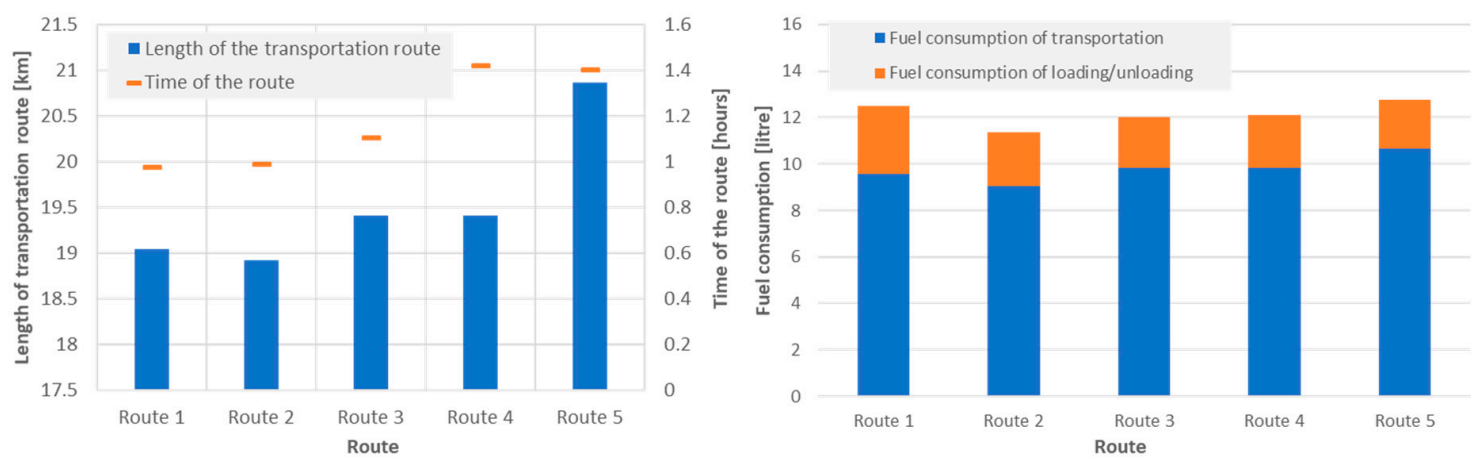

Figure A1. Length of transportation routes, required times, and fuel consumption of transportation and materials handling in Scenario 1.

Figure A2 demonstrates the emission values for each route, including $\mathrm{CO}, \mathrm{CO}_{2}, \mathrm{NO}_{x}, \mathrm{SO}_{2}, \mathrm{PM}$, and HC. Figures A1 and A2 are based on the calculation results summarized in Table 3.
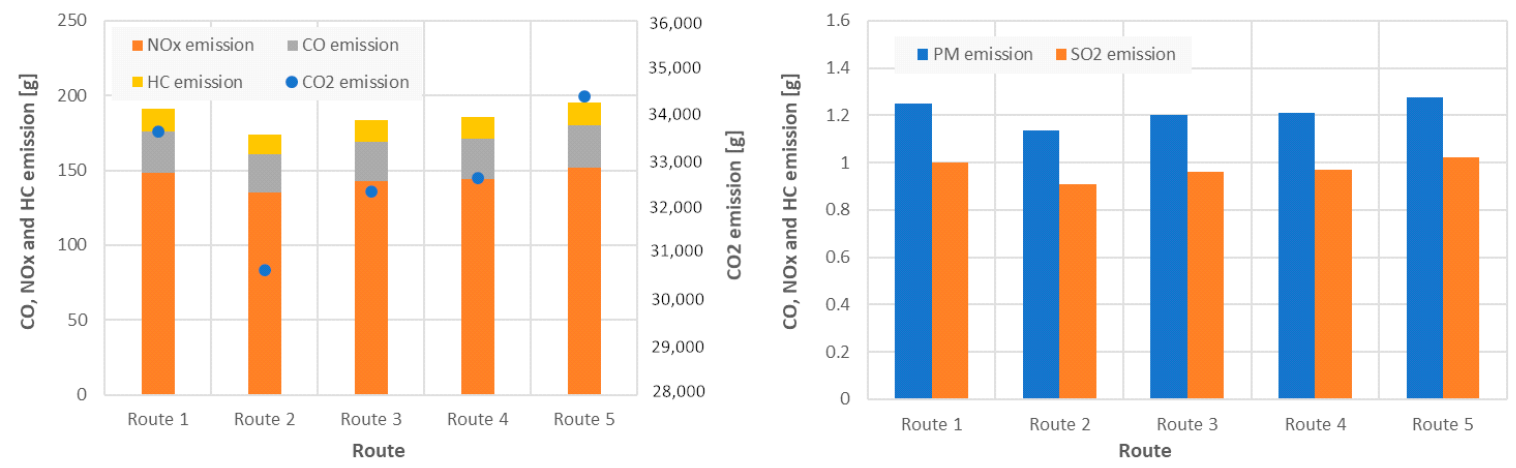

Figure A2. Emission of routes in Scenario 1.

\section{Appendix C}

Appendix $C$ includes some analysis details regarding Scenario 2. Figure A3 shows the calculated length of transportation routes and the required times to perform the whole collection/distribution process, including transportation and materials handling. Figure $\mathrm{A} 4$ demonstrates the emission values for each route, including $\mathrm{CO}, \mathrm{CO}_{2}, \mathrm{NO}_{\mathrm{x}}, \mathrm{SO}_{2}, \mathrm{PM}$, and $\mathrm{HC}$. Figures $\mathrm{A} 3$ and $\mathrm{A} 4$ are based on the calculation results summarized in Table 6.
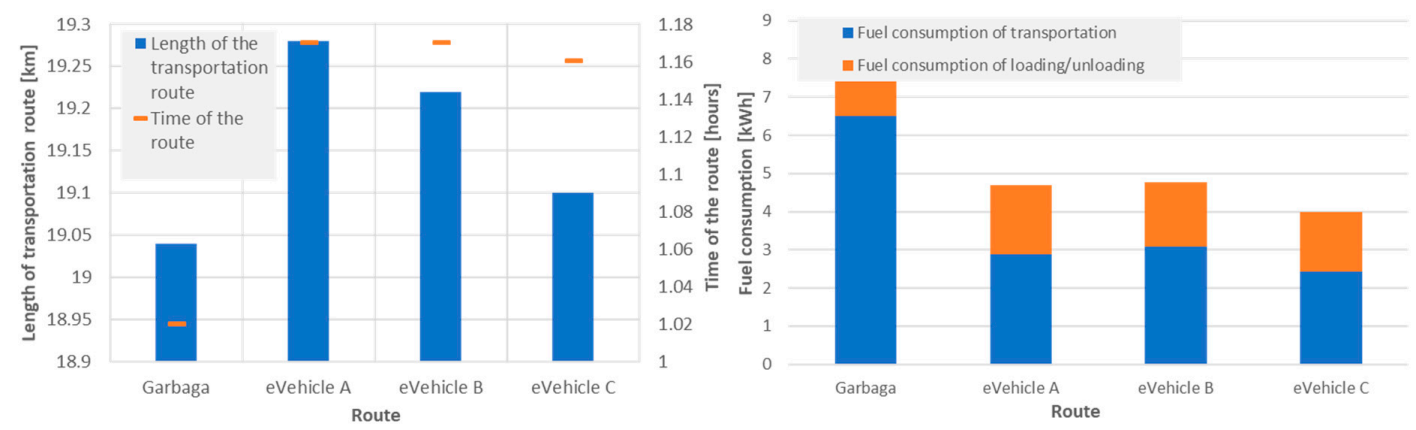

Figure A3. Length of transportation routes, required times, and fuel consumption of transportation and materials handling in Scenario 2. Energy generation source is coal and peak loads are met by natural gas turbines. 

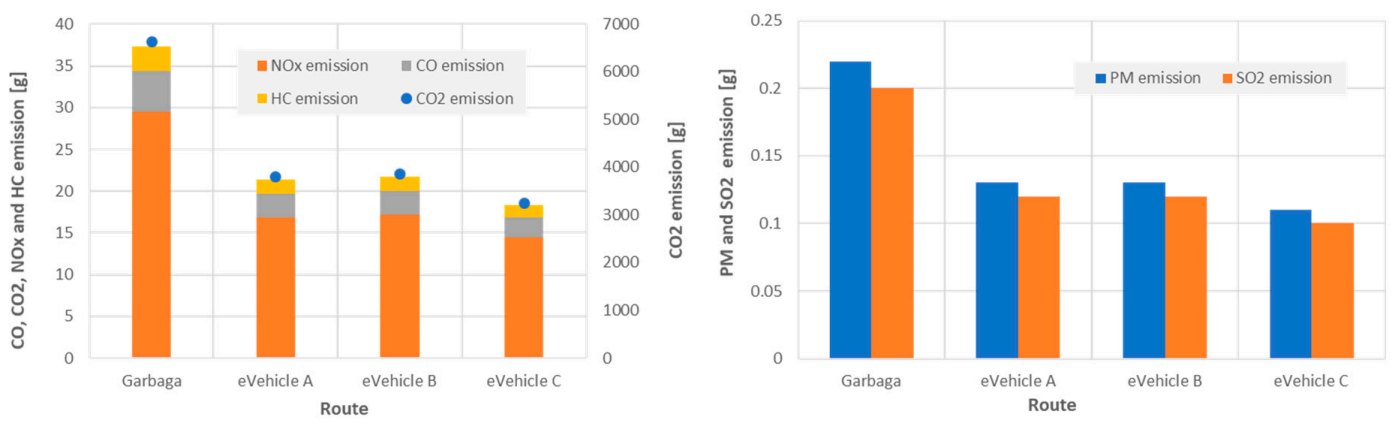

Figure A4. Emission of routes in Scenario 2. Energy generation source is coal and peak loads are met by natural gas turbines.

\section{Appendix D}

Appendix D includes some analysis details regarding emissions in the case of various energy generation sources.

Table A2. Comparison of emission reduction in the case of various energy generation sources.

\begin{tabular}{|c|c|c|c|c|c|c|}
\hline \multirow{2}{*}{ Route ID } & \multicolumn{6}{|c|}{ Emission $^{2}$} \\
\hline & $\mathrm{CO}_{2}$ & $\mathrm{NO}_{\mathbf{x}}$ & $\mathrm{CO}$ & $\mathrm{HC}$ & PM & $\mathrm{SO}_{2}$ \\
\hline \multicolumn{7}{|l|}{ Scenario 1} \\
\hline Total & 163,653 & 722 & 143.6 & 72.7 & 6.06 & 4.84 \\
\hline $\mathrm{PPT}^{1}$ & 5455.1 & 24 & 4.78 & 2.42 & 0.2 & 0.16 \\
\hline \multicolumn{7}{|l|}{ Scenario 2} \\
\hline \multicolumn{7}{|l|}{ Coal } \\
\hline Total & 20,563 & 85.2 & 15.86 & 8.65 & 0.64 & 0.60 \\
\hline $\mathrm{PPT}^{1}$ & 685 & 2.85 & 0.52 & 0.28 & 0.02 & 0.02 \\
\hline $\begin{array}{c}\text { Proportion } \\
\text { Oil }\end{array}$ & $12.57 \%$ & $11.86 \%$ & $11.04 \%$ & $11.90 \%$ & $10.56 \%$ & $12.40 \%$ \\
\hline Total & 16,964 & 70.6 & 13.08 & 7.13 & 0.52 & 0.49 \\
\hline $\mathrm{PPT}^{1}$ & 565 & 2.35 & 0.43 & 0.23 & 0.01 & 0.01 \\
\hline Proportion & $10.37 \%$ & $9.78 \%$ & $9.11 \%$ & $9.82 \%$ & $8.71 \%$ & $10.23 \%$ \\
\hline \multicolumn{7}{|l|}{ Natural gas } \\
\hline Total & 11,535 & 48.1 & 8.89 & 4.85 & 0.35 & 0.33 \\
\hline $\mathrm{PPT}^{1}$ & 384 & 1.60 & 0.29 & 0.16 & 0.01 & 0.01 \\
\hline Proportion & $7.05 \%$ & $6.65 \%$ & $6.20 \%$ & $6.67 \%$ & $5.92 \%$ & $6.95 \%$ \\
\hline \multicolumn{7}{|l|}{ Photovoltaic } \\
\hline Total & 1953 & 8.1 & 1.50 & 0.82 & 0.06 & 0.05 \\
\hline $\mathrm{PPT}^{1}$ & 65 & 0.27 & 0.05 & 0.02 & $<0.01$ & $<0.01$ \\
\hline Proportion & $1.19 \%$ & $1.13 \%$ & $1.05 \%$ & $1.13 \%$ & $1.00 \%$ & $1.18 \%$ \\
\hline \multicolumn{7}{|l|}{ Biomass } \\
\hline Total & 1034 & 4.3 & 0.79 & 0.43 & 0.03 & 0.03 \\
\hline $\mathrm{PPT}^{1}$ & 34 & 0.14 & 0.02 & 0.01 & $<0.01$ & $<0.01$ \\
\hline Proportion & $0.63 \%$ & $0.60 \%$ & $0.56 \%$ & $0.60 \%$ & $0.53 \%$ & $0.62 \%$ \\
\hline \multicolumn{7}{|l|}{ Water/wind } \\
\hline Total & 561 & 2.56 & 0.46 & 0.23 & 0.02 & 0.001 \\
\hline $\mathrm{PPT}^{1}$ & 18.7 & 0.085 & 0.015 & $<0.01$ & $<0.01$ & $<0.01$ \\
\hline Proportion & $0.37 \%$ & $0.35 \%$ & $0.32 \%$ & $0.35 \%$ & $0.31 \%$ & $0.36 \%$ \\
\hline
\end{tabular}

\section{Appendix E}

Appendix E includes the results of a numerical experiment for algorithm performance for a real-world size problem. 


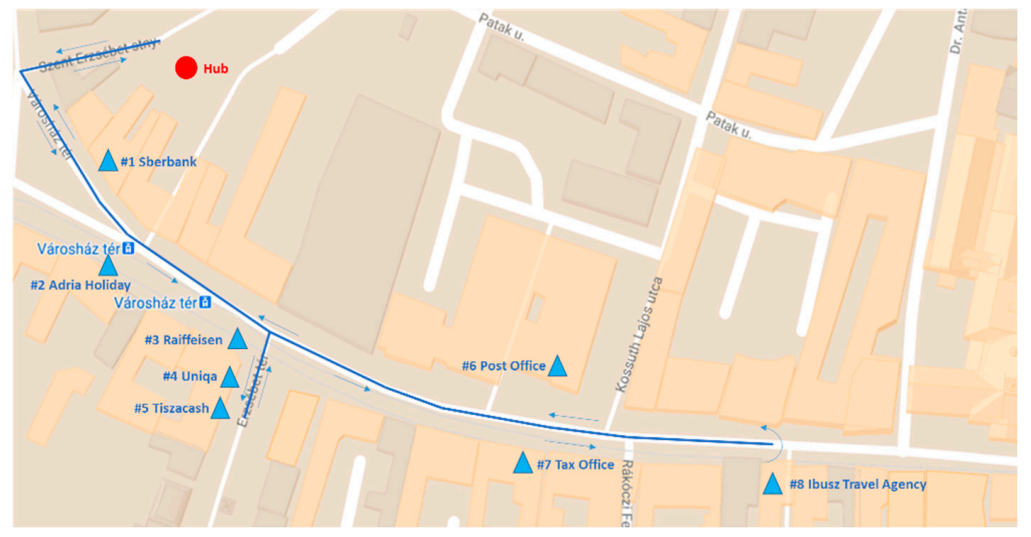

Figure A5. Optimal route of vehicle A in a real-world size problem (Miskolc, Hungary-City Center, western side).

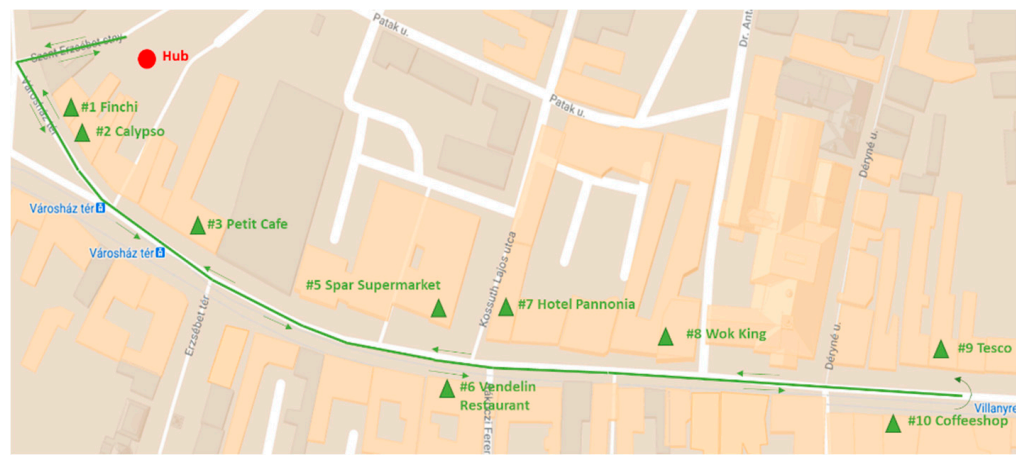

Figure A6. Optimal route of vehicle B in a real-world size problem (Miskolc, Hungary-City Center, western side).

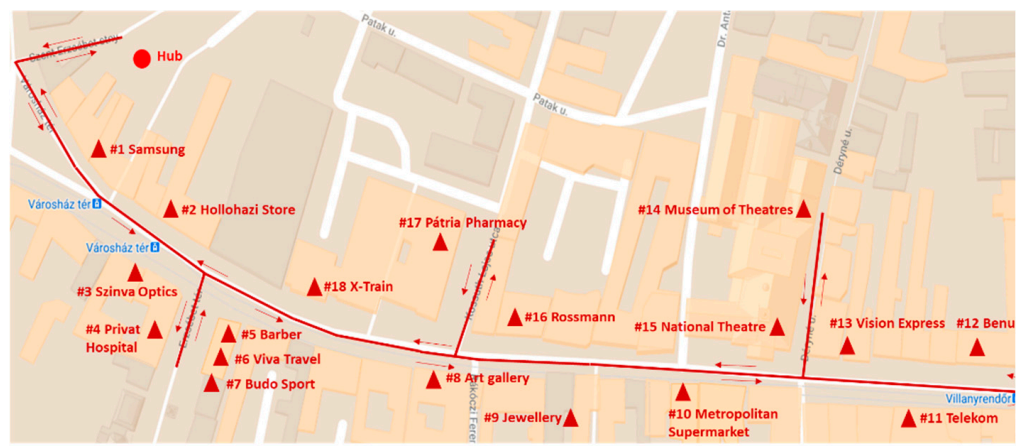

Figure A7. Optimal route of vehicle $C$ in a real-world size problem (Miskolc, Hungary-City Center, western side).

\section{References}

1. Denkena, B.; Mörke, T. Cyber-Physical and Gentelligent Systems in Manufacturing and Life Cycle, 1st ed.; Elsevier: London, UK, 2017; pp. 1-471.

2. Crainic, T.G.; Ricciardi, N.; Storchi, G. Advanced freight transportation systems for congested urban areas. Transport. Res. C-Emer. 2004, 12, 119-137. [CrossRef]

3. Taniguchi, E.; Shimamoto, H. Intelligent transportation system based dynamic vehicle routing and scheduling with variable travel times. Transport. Res. C-Emer. 2004, 12, 235-250. [CrossRef]

4. Munuzuri, J.; Larraneta, J.; Onieva, L.; Cortés, P. Solutions applicable by local administrations for urban logistics improvement. Brit. J. Nurs. 2005, 22, 15-28. [CrossRef]

5. Quak, H.J.; Koster, M.B.M. Exploring retailers' sensitivity to local sustainability policies. J. Oper. Manag. 2007, 25, 1103-1122. [CrossRef] 
6. Braysy, O.; Dullaert, W.; Nakari, P. The potential of optimization in communal routing problems: Case studies from Finland. J. Transp. Geogr. 2009, 17, 484-490. [CrossRef]

7. Sathaye, N.; Horvath, A.; Madanat, S. Unintended impacts of increased truck loads on pavement supply-chain emissions. Transport. Res. A-Pol. 2010, 44,1-15. [CrossRef]

8. Deflorio, F.P.; Gonzalez-Feliu, J.; Perboli, G.; Montreal, C.; Tadei, R. The Influence of Time Windows on the Costs of Urban Freight Distribution Services in City Logistics Applications. Eur. J. Transp. Infrastr. 2012, 12, 256-274.

9. Amaya, J.; Arellana, J.; Delgado-Lindeman, M. Stakeholders perceptions to sustainable urban freight policies in emerging markets. Transport. Res. A-Pol. 2020, 132, 329-348. [CrossRef]

10. Stathopoulos, A.; Valeri, E.; Marcucci, E. Stakeholder reactions to urban freight policy innovation. J. Transp. Geogr. 2012, 22, 34-45. [CrossRef]

11. Munuzuri, J.; Cortés, P.; Grosso, R.; Guadix, J. Selecting the location of minihubs for freight delivery in congested downtown areas. J. Comput. Sci. 2012, 3, 228-237. [CrossRef]

12. Zapata, J.; Arango-Serna, M.D.; Gomez, R.A. Information systems applied to transport improvement. Dyna-Colombia 2013, 80, 77-86.

13. Corni, A.; Coppola, P.; Nuzzolo, A. Freight transport modeling: Review and future challenges. Int. J. Trans. Econ. 2013, 40, 151-181.

14. Crainic, T.G.; Sgalambro, A. Service network design models for two-tier city logistics. Optim. Lett. 2014, 8, 1357-1387. [CrossRef]

15. Cuda, R.; Guastaroba, G.; Speranza, M.G. A survey on two-echelon routing problems. Comput. Oper. Res. 2015, 55, 185-199. [CrossRef]

16. Dai, Z.; Aqlan, F.; Gao, K.; Zhou, Y. A two-phase method for multi-echelon location-routing problems in supply chains. Expert Syst. Appl. 2019, 17, 618-634. [CrossRef]

17. Jie, W.; Yang, J.; Zhang, M.; Huang, Y. The two-echelon capacitated electric vehicle routing problem with battery swapping stations: Formulation and efficient methodology. Eur. J. Oper. Res. 2019, 272, 879-904. [CrossRef]

18. Letnik, T.; Farina, A.; Mencinger, M.; Lupi, M.; Bozicnik, S. Dynamic management of loading bays for energy efficient urban freight deliveries. Energy 2018, 159, 916-928. [CrossRef]

19. Letnik, T.; Marskel, M.; Luppino, G.; Bardi, A.; Bozicnik, S. Review of policies and measures for sustainable and energy efficient urban transport. Energy 2018, 163, 245-257. [CrossRef]

20. Yang, J.; Guo, J.; Ma, S. Low-carbon city logistics distribution network design with resource deployment. J. Clean. Prod. 2016, 119, 223-228. [CrossRef]

21. Behnke, M.; Kirschstein, T. The impact of path selection on GHG emissions in city logistics. Transport. Res. E-Log. 2017, 106, 320-336. [CrossRef]

22. Hu, W.; Dong, J.; Hwang, B.; Ren, R.; Chen, Y.; Chen, Z. Using system dynamics to analyze the development of urban freight transportation system based on rail transit: A case study of Beijing. Sustain. Cities Soc. 2020, 53, 101923. [CrossRef]

23. Kedia, A.; Kusumastuti, D.; Nicholson, A. Acceptability of collection and delivery points from consumers' perspective: A qualitative case study of Christchurch city. Case Stud. Transp. Policy 2017, 5, 587-595. [CrossRef]

24. Munoz-Villamizar, A.; Santos, J.; Montoya-Torres, J.R.; Jaca, C. Using OEE to evaluate the effectiveness of urban freight transportation systems: A case study. Int. J. Prod. Econ. 2018, 197, 232-242. [CrossRef]

25. Chhetri, P.; Kam, B.; Lau, K.H.; Corbitt, B.; Cheong, F. Improving service responsiveness and delivery efficiency of retail networks A case study of Melbourne. Int. J. Retail Distrib. Manag. 2017, 45, 271-291. [CrossRef]

26. Munoz-Villamizar, A.; Santos, J.; Montoya-Torres, J.R.; Velázquez-Martínez, J.C. Measuring environmental performance of urban freight transport systems: A case study. Sustain. Cities Soc. 2020, 52, 101844. [CrossRef]

27. Munoz-Villamizar, A.; Montoya-Torres, J.R.; Faulin, J. Impact of the use of electric vehicles in collaborative urban transport networks: A case study. Transport. Res. D-Tr. E. 2017, 50, 40-54. [CrossRef]

28. Palacios-Argüello, L.; Gonzalez-Feliu, J.; Gondran, N.; Badeig, F. Assessing the economic and environmental impacts of urban food systems for public school canteens: Case study of Great Lyon region. Eur. Transp. Res. Rev. 2018, 10, 37. [CrossRef] 
29. Urzua-Morales, J.G.; Sepulveda-Rojas, J.P.; Alfaro, M.; Fuertes, G.; Ternero, R.; Vargas, M. Logistic Modeling of the Last Mile: Case Study Santiago. Chile. Sustainability 2020, 12, 648. [CrossRef]

30. Ewedairo, K.; Chhetri, P.; Jie, F. Estimating transportation network impedance to last-mile delivery: A Case Study of Maribyrnong City in Melbourne. Int. J. Logit. Manag. 2018, 29, 110-130. [CrossRef]

31. Fancello, G.; Paddeu, D.; Fadda, P. Investigating last food mile deliveries: A case study approach to identify needs of food delivery demand. Res. Transp. Econ. 2017, 65, 56-66. [CrossRef]

32. Mazzarino, M.; Rubini, L. Smart Urban Planning: Evaluating Urban Logistics Performance of Innovative Solutions and Sustainable Policies in the Venice Lagoon-the Results of a Case Study. Sustainability 2019, 11, 4580. [CrossRef]

33. Amaral, R.R.; Semanjski, I.; Gautama, S.; Aghezzaf, E.-H. Urban mobility and city logistics - trends and case study. Promet 2018, 30, 613-622. [CrossRef]

34. Basbas, S.; Bouhouras, E. Sustainable mobility and goods distribution system. the case study of the central area of Thessaloniki. J. Environ. Prot. Ecol. 2012, 13, 603-610.

35. Alho, A.R.; Silva, J.A. Utilizing urban form characteristics in urban logistics analysis: A case study in Lisbon. Portugal. J. Transp. Geogr. 2015, 42, 57-71. [CrossRef]

36. Pelletier, S.; Jabali, O.; Laporte, G. The electric vehicle routing problem with energy consumption uncertainty. Transport. Res. B-Meth. 2019, 126, 225-255. [CrossRef]

37. Cortés-Murcia, D.L.; Prodhon, C.; Afsar, H.M. The electric vehicle routing problem with time windows. partial recharges and satellite customers. Transport. Res. E-Log. 2019, 130, 184-206. [CrossRef]

38. Salabun, W.; Placzewski, K.; Watróbski, J. Multicriteria Approach to Sustainable Transport Evaluation under Incomplete Knowledge: Electric Bikes Case Study. Sustainability 2019, 11, 3314. [CrossRef]

39. Pelletier, S.; Jabali, O.; Laporte, G. 50th Anniversary Invited Article Goods Distribution with Electric Vehicles: Review and Research Perspectives. Transport. Sci. 2016, 50, 3-22. [CrossRef]

40. Lebeau, P.; Macharis, C.; Van Mierlo, J. Exploring the choice of battery electric vehicles in city logistics: A conjoint-based choice analysis. Transport. Res. E-Log. 2016, 91, 245-258. [CrossRef]

41. Watróbski, J.; Malecki, K.; Kijewska, K.; Iwan, S.; Karczmarczyk, A.; Thompson, R.G. Multi-Criteria Analysis of Electric Vans for City Logistics. Sustainability 2017, 9, 1453. [CrossRef]

42. Giordano, A.; Fischbeck, P.; Matthews, H.S. Environmental and economic comparison of diesel and battery electric delivery vans to inform city logistics fleet replacement strategies. Transport. Res. D-Tr. E. 2018, 64, 216-229. [CrossRef]

43. Taefi, T.T. Viability of electric vehicles in combined day and night delivery: A total cost of ownership example in Germany. Eur. J. Transp. Infrast. 2016, 16, 512-553.

44. Bnadeira, R.A.M.; Goes, G.V.; Goncalver, D.V.S.; D'Agosto, M.A.; Oliveira, C.M. Electric vehicles in the last mile of urban freight transportation: A sustainability assessment of postal deliveries in Rio de Janeiro-Brazil. Transport. Res. D-Tr. E. 2019, 67, 491-502. [CrossRef]

45. Teoh, T.; Kunze, O.; Teo, C.-C.; Wong, Y.D. Decarbonisation of Urban Freight Transport Using Electric Vehicles and Opportunity Charging. Sustainability 2018, 10, 3258. [CrossRef]

46. Pelletier, S.; Jabali, O.; Laporte, G. Charge scheduling for electric freight vehicles. Transport. Res. B-Meth. 2018, 115, 246-269. [CrossRef]

47. Fiori, C.; Marzano, V. Modelling energy consumption of electric freight vehicles in urban pickup/delivery operations: Analysis and estimation on a real-world dataset. Transport. Res. D-Tr. E. 2018, 65, 658-673. [CrossRef]

48. Tanco, M.; Cat, L.; Garat, S. A break-even analysis for battery electric trucks in Latin America. J. Clean. Prod. 2019, 228, 1354-1367. [CrossRef]

49. Breunig, U.; Baldacci, R.; Hartl, R.F.; Vidal, T. The electric two-echelon vehicle routing problem. Comput. Oper. Res. 2019, 103, 198-210. [CrossRef]

50. Li, H.; Liu, Y.; Chen, K.; Lin, Q. The two-echelon city logistics system with on-street satellites. Comput. Ind. Eng. 2020, 139, 105577. [CrossRef]

51. Russo, F.; Comi, A. Investigating the Effects of City Logistics Measures on the Economy of the City. Sustainability 2020, 12, 1439. [CrossRef]

52. Rzesny-Cieplinska, J.; Szemlter-Jarosz, A. Environmental sustainability in city logistics measures. Energies 2020, 13, 1303. [CrossRef] 
53. Corni, A.A. modelling framework to forecast urban goods flows. Res. Transp. Econ. 2020, 80, 100827. [CrossRef]

54. Marcucci, E.; Le Pira, M.; Carrocci, C.S.; Gatta, V.; Pieralice, E. Connected shared mobility for passengers and freight: Investigating the potential of crowdshipping in urban areas. In Proceedings of the 5th IEEE International Conference on Models and Technologies for Intelligent Transportation Systems, Naples, Italy, 26-28 June 2017; IEEE: Piscataway, NJ, USA, 2017; pp. 839-843. [CrossRef]

55. Giglio, C.; Palmieri, R. An ICT Solution for Shared Mobility in Universities. In Proceedings of the Second International Afro-European Conference for Industrial Advancement AECIA 2015, Paris, France, 9-11 September 2015; Abraham, A., Wegrzyn-Wolska, K., Hassanien, A., Snasel, V., Alimi, A., Eds.; Springer: Cham, Switzerland, 2016.

56. Breno, A.; Beirigo, F.S.; Negenborn, R.R. Integrating People and Freight Transportation Using Shared Autonomous Vehicles with Compartments. IFAC PapersOnLine 2018, 51, 392-397. [CrossRef]

57. Li, B.; Krushinsky, D.; Reijers, H.A.; Woensel, T.V. The Share-a-Ride Problem: People and parcels sharing taxis. Eur. J. Oper. Res. 2014, 238, 31-40. [CrossRef]

58. Battarra, M.; Cordeau, J.F.; Iori, M. Pickup-and-Delivery Problems for Goods Transportation. In Vehicle Routing: Problems Methods and Applications, 2nd ed.; Toth., P., Vigo., D., Eds.; MOS-Siam: Philadelphia, PA, USA, 2014; pp. 161-191.

59. Wan, F. Study on model and algorithm of inventory routing problem. Phys. Proc. 2012, 24, 1031-1037. [CrossRef]

60. Beraldi, P.; De Maio, A.; Laganà, D.; Violi, A. A pick-up and delivery problem for logistics e-marketplace services. Optim. Lett. 2019, 1-13. [CrossRef]

61. Neghabadi, P.D.; Samuel, K.E.; Espinouse, M.L. Systematic literature review on city logistics: Overview. classification. and analysis. Int. J. Prod. Res. 2019, 57, 865-887. [CrossRef]

62. Hu, W.; Dong, J.; Hwang, B.G.; Ren, R.; Chen, Z. A scientometrics review on city logistics literature: Research trends. advanced theory. and practice. Sustainability 2019, 11, 2724. [CrossRef]

63. Eur-Lex. Concept for Sustainable Urban Mobility Plans. Available online: https://eur-lex.europa.eu/ (accessed on 2 June 2020).

64. Larsen, A.W.; Vrgoc, M.; Christensen, T.H. Diesel consumption in waste collection and transport and its environmental significance. Waste Manage. Res. 2009, 27, 652-659. [CrossRef]

65. Young, C. Excel Solver: Which Solving Method Should I Choose? Available online: https://engineerexcel. com/excel-solver-solving-method-choose/ (accessed on 10 July 2020).

66. Ardeh, M.A. Benchmark Functions for Optimization. Available online: http://benchmarkfcns.xyz/ndimensional (accessed on 19 August 2020).

67. World Nuclear Association. Comparison of Lifecycle Greenhouse Gas Emissions of Various Electricity Generation Sources; World Nuclear Association: London, UK, 2011; pp. 1-12.

68. Tryggestad, C.; Sharma, N.; van de Staaij, J.; Keizer, A. New reality: Electric Trucks and Their Implications on Energy Demand. Available online: https://www.mckinseyenergyinsights.com/ (accessed on 15 May 2020).

69. Orosz, T.; Veres, P.; Bányainé, T.Á. Elektromobilitás az áruszállításban. Multidiscip. Sci. 2019, 9, 88-95. [CrossRef]

70. EU Science Hub. Well-to-Wheels Analyses. Available online: https://ec.europa.eu/jrc/en/jec/activities/wtw (accessed on 26 August 2020).

71. Tamás, P. Innovative business model for realization of sustainable supply chain at the outsourcing examination of logistics services. Sustainability 2018, 10, 210. [CrossRef]

72. Tamás, P. Simulation investigational method for collection and distribution systems. J. Prod. Eng. 2020, 23, 79-82. [CrossRef]

73. Veres, P.; Illés, B.; Landschützer, C. Supply Chain Optimization in Automotive Industry: A Comparative Analysis of Evolutionary and Swarming Heuristics. In Vehicle and Automotive Engineering 2; Jármai, K., Bolló, B., Eds.; Springer: Cham, Switzerland, 2018; pp. 666-676.

(C) 2020 by the authors. Licensee MDPI, Basel, Switzerland. This article is an open access article distributed under the terms and conditions of the Creative Commons Attribution (CC BY) license (http://creativecommons.org/licenses/by/4.0/). 